Geomechanics and Geoengineering: An International Journal, Mar 2008

\title{
The Prediction of Equivalent Granular Steady State Line of Loose Sand with Fines
}

\author{
Md. M. Rahman and S. R. Lo
}

1. Md. Mizanur Rahman

PhD Student

University of New South Wales, ADFA Campus, Canberra, Australia

Email: mmrahman@adfa.edu.au; Fax: +61-2-62688337

2. S. R. Lo

Associate Professor

University of New South Wales, ADFA Campus, Canberra, Australia

Email: rlo@adfa.edu.au; Fax: +61-2-62688337 


\begin{abstract}
:
Void ratio has been used as a state variable for predicting the liquefaction behaviour of soils under the Critical State, sometimes also referred to as the Steady State, framework. Recent publications show that void ratio may not be a good parameter for characterizing sand with fines because the Steady State Line (or curve) in the $e-\log \left(p^{\prime}\right)$ space moves downward with increase in fines content until a threshold value refers to as the threshold fines content "TFC". Recently, an alternative state variable referred to as equivalent granular void ratio has been proposed to resolve this problem. To calculate this alternative state variable, an additional parameter " $b$ " is needed. This parameter " $b$ " represents the fraction of fines that actively participate in the force structure of the solid skeleton. However, predicting the " $b$ " value is problematic. This paper examines the factors affecting the " $b$ " value based on published work on binary packing. This leads to a simple semi-empirical equation for predicting the " $b$ " value based on fines size and fines content. The proposed equations were evaluated with published data sets. Then, the concept of an equivalent granular steady state line is proposed. This concept was used to predict the location of SSLs for sand with different fines content from either the SSL of clean sand or the SSL of sand with a given fines content. The predictions agree well with experimental results.
\end{abstract} Deleted: validated

\title{
KEY WORDS:
}

Void ratio, state variable, Steady State, liquefaction 


\section{INTRODUCTION}

Early laboratory studies on Steady State and liquefaction behaviour were mainly on clean sand although the occurrence of loose sand with fines is not uncommon. Recent studies showed a decrease in liquefaction resistance with addition of fines up to a limiting fines content, but followed by an increase in liquefaction resistance with further increase in fines (Thevanayagam 1998; Xenaki and Athanasopoulos 2003; Yang et al. 2006a). The Steady State (SS) or Critical State (CS) line/curve, which is essential in interpreting static liquefaction, was also found to be dependent on fines content. This lead to some practical difficulties in applying the CS framework to sand with fines because each fines content requires its own SS lines/curves. One of the possible reasons that lead to the lack of a unique SS line/curve independent of fines content may be due to the use of void ratio as a state variable. Some of the fines may simply get trapped in the void space between the host sand and thus provide only secondary contribution to the force chain of the solid skeleton.

Mitchell (1976), arguably, may be the first publication that unambiguously pointed out that the clay particles may not play any active role in the force chain of a granular phase structure. This was confirmed by Kenny (1977) and Troncoso and Verdugo (1985). Kuerbis et al. (1988) proposed the use of a sand skeleton void ratio, $e_{\text {skeleton, }}$ calculated by Eqn (1) below.

$$
e_{\text {skeleton }}=\frac{V_{T} G_{S} \rho_{W}-\left(M-M_{f}\right)}{\left(M-M_{f}\right)}
$$

where $\mathrm{V}_{\mathrm{T}}=$ total volume of soil sample, $\mathrm{G}_{\mathrm{s}}=$ specific gravity of soil, $\rho_{\mathrm{w}}=$ density of water, $M=$ mass of soil, $M_{f}=$ mass of fines. Eqn (1) treats fines as void space. 
Georgiannou et al. (1990) reported that the undrained shear strength of Ham River sand can be correlated to granular void ratio, $e_{g}$, defined by Eqn (2) below.

$$
e_{g}=\frac{\text { Volume of voids }+ \text { volume of clay }}{\text { volume of granular phase }}
$$

Ovando-Shelley and Pérez (1997) coined the term intergranular void ratio. Thevanayagam (1998) also used the term inter-granular void ratio, and calculated $e_{g}$ by Eqn (3) below.

$$
e_{g}=\frac{e+f_{c}}{1-f_{c}}
$$

where, $e=$ void ratio and $f_{\mathrm{c}}=$ fines content in decimal form. However, skeleton void ratio, granular void ratio, and intergranular void ratio have identical meaning: the fines are treated as voids (Chu and Leong 2002). The work of Thevanayagam (1998), among others, suggested, for sand with a small amount of fines less than $12 \%, e_{\mathrm{g}}$ as defined by Eqn (3) should be used as a state parameter in lieu of void ratio. Their work also suggested that $e_{\mathrm{g}}$ in Eqn (3) may not be adequate enough for higher fines content of $25 \%$. To allow the fines to be partially active in the force chain, Thevanayagam et al. $(1999 ; 2000)$ introduced the concept of equivalent granular void ratio, also being referred to as inter-granular contact index void ratio, $e^{*}$, defined as:

$$
e^{*}=\frac{e+(1-b) f_{c}}{1-(1-b) f_{c}}
$$

Where, $b=$ fraction of fines which actively take part in the force structure of the sand skeleton. Eqn (4) can be interpreted as a generalization of Eqn (3) as $b \rightarrow 0, e^{*} \rightarrow e_{\mathrm{g}}$. It is pertinent to note that $e^{*}$ as defined by Eqn (4) has also been referred to by 
different names in the literature: granular void ratio equivalent, contact index void ratio, equivalent intergranular contact index void ratio, equivalent intergranular contact index and equivalent granular void ratio. For simplicity, the last term "equivalent granular void ratio" will be used in this paper.

The concept of an equivalent granular void ratio has been investigated by a number of researchers. For example, Thevanayagam et al. (2002) found that, despite the SS lines in the $e-\log \left(p^{\prime}\right)$ space is highly dependent on the fines content, an approximately unique relationship between $e^{*}$ and $p^{\prime}$ can be obtained by selecting $b=$ 0.25. Similar findings are reported in Ni (2004), Yang et al. (2006a). A number of researchers (Ni et al. 2004; Ni et al. 2005; Thevanayagam 2003; Thevanayagam and Martin 2002) also reported that, for a given combination of sand and fines type, a $b$ -

value can be selected so that the experimental correlation between $e^{*}$ and liquefaction resistance became approximately independent of fines content. However, the following challenges are noted:

The $b$-values reported in literature are back-analysed values. The "input" for the back analysis is a substantial triaxial data set, covering a range of fines content, on steady states or cyclic resistance (for cyclic mobility studies).

$>$ The physical meaning of Eqn (4) implies that the overall matrix is formed by sand, i.e. it is a "fines in sand" material. This necessitates the concept of a threshold fines content (TFC) which is defined as the fines content at which the overall matrix ceases to be formed by sand (Thevanayagam 1998; Xenaki and Athanasopoulos 2003; Yang et al. 2006b). When the fines content exceeds the threshold value, the overall matrix is formed by fines and Eqn (4) ceases to be meaningful. 
A constant " $b$ " value (for a given sand-fines mixtures) irrespective of the fines content is reported in most publications. An exception is Yang et al. (2006b), who suggested $b=0.25$ could be used for fines content less than or equal to $20 \%$, but $b=0.40$ be used at a fines content of $30 \%$. However, the "fines in sand" model of Thevanayagam (1999) implied that fines content can affect the value of " $b$ ". Physical consideration suggested that, if the grain size of the host sand is considerably larger than that of fines, $b \rightarrow 0$ at adequately low fines content.

The work of both Thevanayagam (2001) and Ni et al. (2004) suggested that " $b$ " depended on grain size of fines relative to that of host sand. However, the multiplicity of factors that may influence the $b$-value still need to be clarified.

Therefore the primary objective of this paper is to develop a physically reasonable semi-empirical equation for predicting the value of " $b$ " so that equivalent granular void ratio can be predicted from void ratio, or vice versa, without the need of extensive triaxial test results for a range of fines content. The equivalent granular void ratio so determined will lead to important relationships that are independent of fines content.

\section{BINARY PACKINGS AND FORCE STRUCTURE}

The factors that affect the density of a binary packing has a subtle correspondence to those affecting the $b$-value. A binary packing that can achieve high density (i.e. low void ratio) means that the smaller particles can be fitted within the void space of the larger ones. Thus, unless the fines content is high, the smaller particles may have a secondary role in the force structure in resisting an imposed stress, and the corresponding $b$-value should be low. A binary packing that cannot achieve high 
density means smaller particles must get between the larger ones and participate in the force structure. The corresponding $b$-value, at same fines content, should be higher.

The study of McGeary (1961) on densities achieved by different binary packings of spheres, and placed using a specially designed experimental procedure, was re-analysed by Lade et al. (1998). The findings were presented in a slightly modified form as Fig. 1 of this paper, with the percentage of small spheres in the binary mixture shown as fines content. The void ratio achieved decreases with fines content until a threshold value is reached, but further increase in fines content leads to an increase in void ratio. This leads to a V-shaped curve with the first segment representing a "fines in coarse" packing and the second segment representing a "coarse in fines" packing. Therefore, the trough of the V-curve is analogous to the concept of threshold fines content, TFC. An idealized bi-linear curve is also shown in Fig. 1. The first segment of this idealized curve was computed by assuming all the smaller spheres were packed between the voids of the larger spheres, whereas the second segment was deduced based on replacing a given percentage of the smaller spheres (which contain void space) with a solid larger sphere. For $\mathrm{D} / \mathrm{d}>6.5$, where " $\mathrm{D}$ " is the diameter of the larger sphere and " $\mathrm{d}$ " is that of smaller sphere, the void ratios achieved were closed to the idealized line. These spheres trapped in the voids will only make a minor contribution to the force structure (if loading is imposed on the binary packing). If $\mathrm{D} / \mathrm{d}<4.7$, the void ratios achieved were significantly higher because significant fraction of the smaller spheres were located between the larger spheres. These smaller spheres located between the larger one will actively participate in the force structure (if loading is imposed on the binary packing). The V-shape curve becomes "flatter" relative to the ideal curve with increase in fines 
content, thus implying that more smaller spheres are located in the voids between the larger ones.

Fig. 2 was reproduced, with minor formatting modifications, from Lade et al. (1998). The "lowest void ratios" is defined by the trough (transition) points of the Vshaped curves of Fig. 1. At high size ratio, say D/d $>9$, the "lowest void ratio" only reduces slightly with increase in $\mathrm{D} / \mathrm{d}$. For $\mathrm{D} / \mathrm{d}<6$, the "lowest void ratio" changes rapidly with $\mathrm{D} / \mathrm{d}$ because more smaller spheres have to get in between the larger spheres so that the void spaces are open up enough to accommodate the smaller spheres (of an increased diameter). One can also infer a "sharp bend" delineating these two regimes at $\mathrm{D} / \mathrm{d} \cong 7$. This value is consistent with the geometric calculation of fitting a smaller sphere between larger ones (Lade at al 1998).

\section{PREDICTION OF “ $b$ "-VALUE}

\subsection{Factors affecting " $b$ "-value}

It is pertinent to emphasize that there is a correspondence between the void ratio achieved in the binary packings study of McGeary (1961) and the $b$-value. The conditions that lead to a higher "void ratio" of these binary packing will also leads to a higher fraction of the fines participating in the force structure of the sand-fines mix. Therefore, the detailed analysis on binary packing as presented in the previous subsection implies that the $b$-value can be represented by a functional relationship $b=$ $F\left(\chi, f_{\mathrm{c}}\right)$ that has the following attributes.

1. The concept of a threshold fines content, TFC (for delineating the regime of "fines in sand" from "sand in fines") is valid and essential. The trough of the 
experimental V-shape curves presented in Fig. 1 corresponds to a switch from "fines in sand" to a "sand in fines" model

2. For $f_{c}<\mathrm{TFC}$, the " $b$ " value increases with fines content. With increasing fines content, the first segment of the experimental V-shape curves gradually deviates more from the idealized one (Fig. 1). Such a deviation implies that more fines are located between the coarse grains and thus a higher " $b$ " value.

3. By assuming a correspondence between the transition void ratio and $b$-value, one can infer from Fig. 2 the concept of a critical size ratio, denoted as $(D / d)_{\text {crit }}$, that delineates two distinct zones. In the regime of $D / d>>(D / d)_{\text {crit }}$, " $b$ " increases slowly with increase in fines content (because the fines can migrate into the void space between the coarse particles). In the regime of $\mathrm{D} / \mathrm{d}$ $<(\mathrm{D} / \mathrm{d})_{\text {crit, }}$ " $b$ " increased rapidly with increase in fines content.

4. Along the same argument as point 3 above, Fig. 2 shows that there is a transition region around $(\mathrm{D} / \mathrm{d})_{\text {crit }}$ where " $b$ " increases gradually with fines content because the fines can migrate into the void space between the large particles.

\subsection{Prediction equation}

In this section, the functional relationship $b=F\left(\chi, f_{\mathrm{c}}\right)$ is developed using a semiempirical approach. If the sand and fines are not single size, we will instead use $\mathrm{D}_{10}$ for defining the size of the host sand and $\mathrm{d}_{50}$ for that of fines following the argument of $\mathrm{Ni}$ et al (2004). Therefore the size ratio, $\chi$, in general is defined as $\mathrm{D}_{10} / \mathrm{d}_{50}$. Evidently for a mixture where both the host sand and the fines are single size, $\chi$ reduces to $\mathrm{D} / \mathrm{d}$. This function has to be able to simulate the four mathematical 
attributes discussed in the previous sub-section, and yet has a simple form. Eqn (5) given below satisfies such a requirement.

$$
b=\left[1-\exp \left(-m \frac{\left(f_{c} / T F C\right)^{n}}{k}\right)\right] \cdot\left(r \frac{f_{c}}{T F C}\right)^{r}
$$

Where, $f_{c}=$ fines content, $r=\chi^{-1}=\mathrm{d} / \mathrm{D}, k=\left(1-r^{0.25}\right)$, and $m, n$ are two empirical constants. The first factor gives the general shape of the $b-\chi$ curve as required by attributes (3) and (4). The second factor of the equation ensures that $b \rightarrow 0$ as $f_{c .} \rightarrow 0$.

To further simplifies the equation, we assign $n=1$. The parameter " $m$ " can be determined by calibrating against the data set of Thevanayagam et al. (2002) as explained in the subsequent sub-section.

\subsection{Determination of Parameter " $m$ "}

Thevanayagam et al. (2002) published a comprehensive set of data showing the influence of fines content on the location of SSL as illustrated in Fig. 3. The SSL initially shifted downwards with increase in fines content but the trend was reversed at higher fines content. The fines content defining the lowest position of the SSL is the reversal point, thus the TFC. To determine this value objectively, $e_{100}$ was plotted against fines content as presented in Fig. 4, where $e_{\mathrm{SS}}(100)$ is the void ratio on the SSL at $p_{\mathrm{SS}}^{\prime}$ of $100 \mathrm{kPa}$. The reversal point defines the TFC at $p_{\mathrm{SS}}^{\prime}$ of $100 \mathrm{kPa}$. To examine the sensitivity of TFC on $p_{\mathrm{SS}}^{\prime}$, the above exercise was repeated using $e_{\mathrm{SS}}$ at $p^{\prime}$ of 50 and 200 respectively. The resultant plots presented shown in the same figure shows that the fines content at the reversal point is only slightly affected by $p$ 'ss. However, to reduce variability, TFC standardized at $p$ 'ss of $100 \mathrm{kPa}$. For Eqn (5) to 
be valid, the equivalent granular void ratio calculated using Eqn (5) should give a unique SSL in the $e^{*}-\log \left(p^{\prime}\right)$ space. The predicted " $b$ " value is only meaningful if the SS data points can be described by a single relationship. This consideration provides the basis for deducing the value of " $m$ " from the data set of Thevanayagam et al. (2002) by the following procedure.

1. Assume a value of " $m$ " and thus calculate the corresponding $b$-values for all the data points using Eqn (5).

2. Calculate the value of $e^{*}$ using the calculated $b$-value and plot the corresponding $\left(e^{*}, p^{\prime}\right.$ ss $)$ data points.

3. Establish a best-fit trend line/curve for these $\left(e^{*}, p_{\mathrm{ss}}^{\prime}\right)$ data points and calculate the corresponding "sum of residues" following conventional statistical analysis techniques.

4. Repeat steps 1 to 3 until and that the best fit trend line/curve appears to well describe the data points and that "the sum of residues" is at a minimum.

The above procedure gave $m=0.30$ and an essentially single relationship between $e^{*}$ and $\log \left(p^{\prime} s S\right)$. As discussed in a later section, this value of " $m$ " was found to be appropriate for other data sets published by other researchers. Therefore, Eqn (5) becomes:

$$
b=\left[1-\exp \left(-0.3 \frac{\left(f_{c} / T F C\right)}{k}\right)\right] \cdot\left(r \frac{f_{c}}{T F C}\right)^{r}
$$

\subsection{Attributes of Prediction Equation}

The variation of " $b$ " with $\chi$, for a range of fines content, is presented in Fig. 5a. The plot is normalized with $b(20)$, the " $b$ " value at $\chi=20$ so that plots corresponding to 
different fines content can be compared. It has the characteristic shape of Fig. 2. The resultant variation of " $b$ " with fines content, normalized relative to threshold fines content, is shown in Fig. 5b. The plots showed the rate of increase in " $b$ " with fines content is initially low and the rate changes at higher fines content. Furthermore the rate increases with reduction in $\chi$. Both attributes are consistent with inferences from the binary packing concept discussed in the previous section.

\subsection{Prediction of TFC}

The value of TFC reported in published literature is the range of $25 \%$ to $50 \%$. However, the range reduces to $30 \%$ to $41 \%$ if only data points that satisfy the definition of TFC adopted in this paper are included. Although an average value of $35 \%$ may be selected as a first approximation, a simple method for predicting TFC is presented by studying the influence of $\chi$ on TFC using published data. For data sets on the effect of fines content on cyclic resistance, TFC is also defined by the fines content where the influence of fines content on cyclic resistance reverses in direction. This gives a total of nine data points. Fig. 6 shows that those data points reveal a distinct pattern with three important attributes:

- Firstly, TFC is at minimum value when particle diameter ratio $(\chi)$ is approximately at $(\mathrm{D} / \mathrm{d})_{\text {crit }}$. This is consistent with the binary packing consideration that at $(D / d)_{\text {crit, }}$ a minimum number of one small particle can be fit in between the gap of large particles. Thus, it is expected to achieve minimum TFC around $(\mathrm{D} / \mathrm{d})_{\text {crit. }}$.

- Secondly, increase of $\chi$ beyond the turning point (when TFC is at a minimum) leads to a gradual increase of $\mathrm{TFC}$ to an asymptotic value. For a binary packing point of view, as the small particles get smaller in size, more particles 
can fit in the same void space between the large particles (thus giving a higher TFC) but there is an asymptotic limit to this increase.

- Thirdly, when diameter ratio is less than (D/d) crit, TFC again increases rapidly. This is because the small particles open up the gaps between large particles and give more space for the small particles to get it.

These features can be modeled by the following equation with three constants:

$$
T F C=A\left(\frac{1}{1+e^{\alpha-\beta \chi}}+\frac{1}{\chi}\right)
$$

The coefficient of $A$ is the asymptotic value of 0.40 irrespective of the value of $\alpha$ and $\beta$. The other two parameters $\alpha$ and $\beta$ are determined to yield a minimum TFC around $(\mathrm{D} / \mathrm{d})_{\text {crit }}$ and the maximum TFC data point corresponding to the smallest $\chi$ of $\sim 2.0$. Eqn (6), also give a general shape that fits the data points well.

\section{VERIFICATION}

To ensure the proposed equation (5a), with $m=0.30$, has general applicability, a validation exercise was conducted on nine different data sets extracted from published literatures. These data sets cover a wide range of sand and fines from six countries. A brief summary of the data sets is presented in Table 1. Two types of behaviour were examined: the SS data points from monotonic undrained shearing and the cyclic resistance behaviour from cyclic triaxial testing. The validation procedure is as follows. 
- Determine TFC from Eqn. (6), if not enough data is available to get TFC as mentioned in section 3.3.

- Calculate the " $b$ " values using Eqn (5a).

- Convert the void ratios of the published data to equivalent granular void ratios using Eqn (4) .

- Examined whether a unique behaviour trend independent of fines content can be obtained utilizing the equivalent granular void ratio as the alternative state variable.

Two input parameters, $\chi, f_{c}$ are required in the prediction.

\subsection{Steady State behaviour from monotonic undrained Shearing}

Fig. 7 showed a plot of SS data points in terms of both equivalent granular void ratio and global void ratio. For the sake of clarity, individual data points corresponding to equivalent granular void ratio are presented; but the source data points based on void ratio are located in the hatched area. Note that the lower bound of the hatched area is defined by the trend line, not individual data point, and thus is a good indication of the spread of the SSL based on global void ratio.

Yang et al. (2006a) studied the influence of including Chengbei non-plastic silt in Hokksund sand. Their SS lines/curves based on void ratio manifest considerably dependence on the fines content as indicated in the hatched area of Fig.

7. The difference in the location of the trend line between clean sand and that with $30 \%$ fines is about 0.33 in terms of void ratio. However, the SS data points based on $e^{*}$ essentially follow a unique relationship independent of fines content with a maximum scatter in terms of $e^{*}$ is about 0.03 around average trend line.

Huang et al. (2004) performed a series of laboratory tests on reconstituted sample of Mai Liao Sand (MLS) with silty fines from Central Western Taiwan. Their 
SS lines/curves based on void ratio manifest considerably dependence on the fines content as indicated in the hatched area of Fig. 8. The difference in the location of the trend line between clean sand and $30 \%$ fines is about 0.34 in terms of void ratio. However, the SS data points based on $e^{*}$ calculated with Eqns (4) and (5a) are all located within a narrow band. The maximum scatter in terms of $e^{*}$ is about 0.04 around average trend line.

$\mathrm{Ni}$ et al. (2004) reported the influence of a non-plastic fines on Old Alluvium sand from Singapore. Their SS lines/curves based on void ratio manifests evident dependence on the fines content as indicated in the hatched area of Fig. 9. The difference in the location of the trend line between clean sand and $9 \%$ fines is about 0.11 in terms of void ratio. However, the SS data points based on $e^{*}$ essentially follow a unique relationship irrespective of fines content, with a maximum scatter in terms of $e^{*}$ around the average trend line is about 0.03 .

Zlatovic and Ishihara (1995) reported the influence of fines on Toyoura sand. The fines are derived from milled Toyoura sand. Their SS lines/curves based on void ratio manifest considerably dependence on the fines content as indicated in the hatched area of Fig. 10. The difference in the location of the trend line between clean sand and that with $30 \%$ fines is about 0.45 in terms of void ratio. However, the SS data points based on $e^{*}$ calculated with Eqns (4) and (5a) are all located within a narrow band, despite this data set was obtained by specimens prepared with a range of placement methodology. The maximum scatter in terms of $e^{*}$ is about 0.04 around average trend line.

Thevanayagam et al. (2002) presented SS data points for Foundary sand mixed with fines derived from crushed silica. Their SS lines/curves based on void ratio manifest considerably dependence on the fines content as indicated in the hatched 
area of Fig. 11. The difference in the location of the trend line between clean sand and that with $25 \%$ fines is about 0.38 in terms of void ratio. However, the SS data points based on $e^{*}$ calculated with Eqns (4) and (5a) are all located within a narrow band. The maximum scatter in terms of $e^{*}$ around the average trend line is about 0.04 .

Based on the above comparisons, the SS lines/curves in the $e^{*}-\log \left(p^{\prime}\right)$ space may be approximated by a single relationship irrespective of fines content. This single relationship will be referred to as the Equivalent Granular Steady State Line (EGSSL).

\subsection{Cyclic resistance behaviour}

Despite the prediction of " $b$ " and thus $e^{*}$ is determined by the desire to obtained a single equivalent granular SSL, it is demonstrated in this section that cyclic resistance can also be correlated to $e^{*}$ in a manner that is approximately independent of fines content. Cyclic resistance (CR), also referred to as cyclic resistance ratio (CRR), is defined as the cyclic stress ratio (CSR) that triggers "initial liquefaction". The definition of CR, CSR, and "initial liquefaction" are defined in Appendix A.

Vaid (1994) performed cyclic triaxial tests on Brenda 20/200 sand, an angular tailing sand with non-plastic fines to study the influence of fines content on the correlation between cyclic resistance and void ratio. The cyclic resistance versus void ratio data, for a range of fines content, spread over the hatched area in Fig 12. At a fines content of $21 \%$, the correlation shifted downwards relative to clean sand by about 0.30 . However, the cyclic resistance versus $e^{*}$ relationship is essentially independent of fines content, with a maximum scatter of 0.03 in $e^{*}$ around the trend line/curve. 
Polito (1999) preformed cyclic triaxial tests on Yatesville sand with Yatesville fines. Yatesville sand is a poorly graded, medium to fine sand obtained from a dam site in Louisa County, Kentucky. The fines was the fine-grained portion of Yatesville silty sand. The cyclic resistance versus void ratio data points, for a range of fines content, spread over the hatched area in Fig 13. At a fines content of $37 \%$, the correlation shifted downwards relative to clean sand by about 0.45 . However, if $e^{*}$ is used as the parameter in lieu of void ratio, the data points are located within a narrow band with a maximum scatter of 0.08 in $e^{*}$ around the trend line/curve.

Polito and Martin (2001) preformed a series of cyclic triaxial tests on Monterey No. 0/30 sand with Yatesville fines. The cyclic resistance versus void ratio data points, for a range of fines content, spread over the hatched area in Fig 14. At a fines content of $25 \%$, the correlation shifted downwards relative to clean sand by about 0.42 . However, if $e^{*}$ is used as the parameter in lieu of void ratio, the data points are located within a narrow band with a maximum scatter of 0.05 in $e^{*}$ around the trend line/curve.

Thevanayagam and Martin (2002) studied the effect of fines on cyclic liquefaction using Ottawa sand with non-plastic silt. The number of cycles required to achieve initial cyclic mobility at an imposed cyclic stress ratio of $0.20, \mathrm{~N}_{\mathrm{L}}$, was used as a parameter for studying the influence of fines. $\mathrm{N}_{\mathrm{L}}$ may be considered as an indicator of CR. The hatched area of Fig. 15 showed that the correlation in the $e-\mathrm{N}_{\mathrm{L}}$ space manifests considerable dependence on fines content. At a fines content of $25 \%$, the correlation shifted downwards relative to clean sand by about 0.37 . However, if $e^{*}$ is used as the parameter in lieu of void ratio, the data points are located within a narrow band with a maximum scatter of 0.06 in $e^{*}$ around average trend line. 
Based on the above comparisons, the cyclic resistance of loose sand with fines can also be correlated to $e^{*}$ irrespective of fines content.

\section{APPLICATION}

Equivalent granular void ratio can be used to predict SSL of sand with fines without performing extensive number of triaxial tests on sand with fines. In earlier section it is mentioned that equivalent granular SSL is essentially independent of fines content. and therefore the SSL of clean sand is identical to the equivalent granular SSL. This provide the means for predicting the SSL of sand with fines (of any fines content less than that of TFC) without the need to conduct a large set of triaxial tests.

1. Determine TFC using Eqn (6). The only input parameter is $\chi$.

2. For any $p_{\text {ss }}^{\prime}$, determine the corresponding void ratio of the host sand from the SSL of the host sand. This void ratio is in fact $e^{*}$ of sand with fines.

3. For predicting the SSL of a sand at a certain fines content, calculate the corresponding global void ratio of sand with fines, $e$, by:

- First calculate TFC and " $b$ " using Eqn. (6)

- Calculate $e$ from $e^{*}$ with Eqn. (5a)

4. Repeat steps 4 and 5 for other values of $p^{\prime}$ sS so that a complete SSL for sand with fines is generated.

Two examples are presented below to demonstrate the effectiveness of this process.

\subsection{Example 1}

The data of clean sand presented in Thevanayagam et al. (2002) is used to predict SSL of sand with $25 \%$ fines. The predicted SSL of sand with $25 \%$ fines is compared with 
actual data points as measured from triaxial testing in Fig. 16. Satisfactory agreement is obtained.

\subsection{Example 2}

The data presented by Bobei and Lo (2005) for Sydney sand with 10\% fines are use as the input information for predicting the SSL for sand with $20 \%$ fines.

In this example, the SSL for clean sand is first predicted with slightly modified steps A to C below.

Step A: Determine the TFC value using Eqn (6). This step is identical to step 1 of Example 1.

Step B: For any $p^{\prime}$ ss, determine the corresponding global void ratio from the known SSL of sand with $10 \%$ fines.

Step C: This global void ratio is then used to calculate instead the corresponding equivalent granular void ratio, $e^{*}$ using Eqns. (4), (5a), (6) with $f_{\mathrm{c}}=0.10$. This equivalent granular void ratio is in fact global void ratio for clean sand. Repetition of steps B to C gives the equivalent granular SSL which is also the SSL for clean sand (based on overall void ratio). From the SSL of clean sand, the SSL for sand with $20 \%$ fines can then be deduced following the procedure of example 1 . In this example, the SSL for clean sand and that of sand with $20 \%$ fines were predicted from the SSL of sand with $10 \%$ fines.

These two predicted SSLs are then compared with experimental results of the authors and Bobei and Lo (2005). Five tests for clean sand $(\mathrm{FC}=0 \%)$ and four tests with $\mathrm{FC}=20 \%$ were conducted by authors following the same specimen preparation 
and testing methodology of Bobei and Lo (2005). As evident from the comparison presented in Fig. 17, good agreement between prediction and test data is achieved.

\section{CONCLUSIONS}

A simple method has been developed for predicting the influence of fines content on the SSL under triaxial compression. This method is based on the framework of i) a $b$ value that models the fraction of fines that actively participate in the force structure of the solid skeleton, and ii) the use of an equivalent granular void ratio, $e^{*}$, in lieu of the void ratio as the alternative state parameter, and iii) the conceptual requirement of a $\underline{\text { single Equivalent Granular Steady State line. As an integral part of this methodology, }}$ a simple semi-empirical prediction-equation, with " $b$ " being a function of both fines content and size ratio, has been developed. This equation, although semi-empirical in nature, is consistent with physical considerations on the role and meaning of " $b$ " and equivalent granular void ratio. This approach is valid for fines content less than the threshold value so that a fines-in-sand model is valid.

This prediction equation only requires simple input parameters, viz, size ratio (which represents the ratio between the diameters of host sand and that of fines), fines content and threshold fines content. Thus the equivalent granular void ratio can be determined without the need of knowing the Steady State or cyclic liquefaction behaviour for a range of fines content as a pre-requisite.

The validity of this equation was evaluated against several published data sets. The findings for these data sets are:

- The requirement of a single steady state line irrespective of fines content in the equivalent granular void ratio versus effective mean stress space can be 
achieved by Eqns (4) and (5a). This single relationship will be referred to as the "equivalent granular Steady State Line/Curve".

- The proposed equations (4) and (5a) also leads to a single correlation, irrespective of fines content, between cyclic resistance and equivalent granular void ratio is obtained.

- The proposed equation also leads to an approximate correlation, irrespective of fines content, between $\mathrm{N}_{\mathrm{L}_{-}}$and equivalent granular void ratio, where $\mathrm{N}_{\mathrm{L}}$ is the number of load cycles to induce initiation of cyclic liquefaction under an imposed stress ratio of 0.20 .

This means that provided that the Steady State or cyclic liquefaction behaviour for clean sand is known, the behaviour for sand with fines can be inferred provided that the fines content is less than the threshold value. However, the semi-empirical nature of Eqn (5a) needs to be recognized and further research is needed before one can generalized the findings to all sand-fines mixtures. 


\begin{abstract}
APPENDIX A

\section{Definition of cyclic resistance and cyclic stress ratio}

Cyclic Resistance (Ishihara 1993) is defined as the cyclic stress ratio (CSR) that will trigger "initialization of liquefaction" in 20 load cycles. Initialization of liquefaction (sometimes refers to as manifestation of cyclic mobility) is defined by a cyclic strain of 5\% double amplitude. It is pertinent to note that slight different (and less objective) criteria had been used in earlier work. Provided the same definition was used in a given data set, it will not affect evaluation of the findings in this paper: the validity (or otherwise) of a single correlation between $\mathrm{CR}$ and $e^{*}$.
\end{abstract}

Cyclic stress ratio (CSR) is defined as follows:

$$
\begin{gathered}
C S R=\frac{\sigma_{d}}{2 \sigma_{c 0}^{\prime}} \\
\sigma_{d}=\frac{q_{p}-q_{t}}{2}
\end{gathered}
$$

where $q$ is the deviator stress, subscripts " $p$ " and " $t$ " denote peak and trough state respectively of loading cycles, and $\sigma_{c 0}^{\prime}=$ effective consolidation stress prior to shearing. 


\section{References}

Bobei, D. C., and Lo, S. R. (2005). "Reverse behaviour and critical state of sand with small amount of fines." The Proceedings of the 16th International Conference on Soil Mechanics and Geotechnical Engineering (16ICSMGE), Japan, 475478.

Chu, J., and Leong, W. K. (2002). "Effect of fines on instability behaviour of loose sand." Géotechnique, Vol. 52(10), 751-755.

Georgiannou, V. N., Burland, J. B., and Hight, D. W. (1990). "The undrained behaviour of clayey sands in triaxial compression and extension." Géotechnique, Vol. 40(3), 431-449.

Huang, Y.-T., Huang, A.-B., Kuo, Y.-C., and Tsai, M.-D. (2004). "A laboratory study on the undrained strength of silty sand from Central Western Taiwan." Soil Dynamics and Earthquake Engineering, Vol. 24, 733-743.

Ishihara, K. (1993). "Liquefaction and flow failure during earthquakes." Géotechnique, Vol. 43(3), 351-415.

Kenney, T. C. (1977). "Residual strength of mineral mixture." Proc. 9th International Conference of Soil Mechanics and Foundation Engineering, 155-160.

Kuerbis, R., Negussey, D., and Vaid, Y. P. (1988). "Effect of gradation and fine content on the undrained response of sand." Hydraulic fill structure, Geotechnical Special Publication 21, ASCE, New York, 330-345.

Lade, P. V., Liggio, C. D., and Yamamuro, J. A. (1998). "Effects of non-plastic fines on minimum and maximum void ratios of sand." Geotechnical Testing Journal, Vol. 21(4), 336-347.

McGeary, R. K. (1961). "Mechanical packing of spherical particles." Journal of the American Ceramic Society, Vol. 44(10), 513-522.

Mitchell, J. K. (1976). Fundamental of soil behaviour, 1st edition, John Wiley \& Sons, Inc.

Ni, Q., Tan, T. S., Dasari, G. R., and Hight, D. W. (2004). "Contribution of fines to the compressive strength of mixed soils." Géotechnique, Vol. 54(9), 561-569.

Ni, Q., Tan, T. S., Dasari, G. R., and Hight, D. W. (2005). "Discussion: Contribution of fines to the compressive strength of mixed soils." Géotechnique, Vol. 55(8), 627-628.

Ovando-Shelley, E., and Pérez, B. E. (1997). "Undrained behaviour of clayey sands in load controlled triaxial tests." Géotechnique, Vol. 47(1), 97-111.

Polito, C. P. (1999). "The effects of non-plastic and plastic fines on the liquefaction of sandy soils," $\mathrm{PhD}$ thesis in Civil Engineering, The Virginia Polytechnic Institute and State University, Blacksburg, USA.

Polito, C. P., and Martin, J. R. (2001). "Effects of nonplastic fines on the liquefaction resistance of solids." Journal of Geotechnical and Geoenvironmental Engineering, Vol. 127(5), 408-415.

Thevanayagam, S. (1998). "Effect of fines and confining stress on undrained shear strength of silty sands." Journal of Geotechnical and Geoenvironmental Engineering, Vol. 124(6), 479-491.

Thevanayagam, S. (1999). "Effect of fines and confining stress on the undrained shear strength of silty sands - Closure." Journal of Geotechnical and Geoenvironmental Engineering, Vol. 125(11), 1024-1027.

Thevanayagam, S. (2001). "Role of intergranular contacts on the mechanisms causing liquefaction and slope failures in silty sands." Annual project summary report, 
USGS Award Number: 01HQGR0032, US Geological Survey, Department of Interior, USA.

Thevanayagam, S. (2003). "Role of intergranular contacts on mechanisms causing liquefaction and slope failures in silty sands." Final Report. USGS Award No. 01HQGR0032 and 99HQGR0021, US Geological Survey, Department of Interior, USA.

Thevanayagam, S., Fiorillo, M., and Laing, L. (2000). "Effect of non-plastic fines on undrained cyclic strength of silty sands." ASCE Geotechnical Special Publication, 99-91.

Thevanayagam, S., and Martin, G. R. (2002). "Liquefaction in silty soils-screening and remediation issues." Soil Dynamics and Earthquake Engineering, Vol. 22(9-12), 1035-1042.

Thevanayagam, S., Shenthan, T., Mohan, S., and Liang, J. (2002). "Undrained fragility of clean sands, silty sands, and sandy silts." Journal of Geotechnical and Geoenvironmental Engineering, Vol. 128(10), 849-859.

Troncoso, J. H., and Verdugo, R. (1985). "Silt content and dynamic behaviour of tailing sands." Proc. 11th International Conference on Soil Mechanics and Foundation Engineering, 1311-1314.

Vaid, Y. P. (1994). "Liquefaction of silty soils in Ground Failure under Seismic Conditions." Geotech. Spl. publ. No. 44, S. Prakash and P. Dakoulas (eds.), 116.

Xenaki, V. C., and Athanasopoulos, G. A. (2003). "Liquefaction resistance of sandsilt mixtures: an experimental investigation of the effect of fines." Soil Dynamics and Earthquake Engineering, Vol. 23, 183-194.

Yang, S. L., Lacasse, S., and Sandven, R. F. (2006a). "Determination of the transitional fines content of mixtures of sand and non-plastic fines." Geotechnical Testing Journal, Vol. 29(2), 102-107.

Yang, S. L., Sandven, R., and Grande, L. (2006b). "Instability of sand-silt mixtures." Soil Dynamics and Earthquake Engineering-11th International Conference on Soil Dynamics and Earthquake Engineering (ICSDEE): Part II, Vol. 26(2-4), 183-190.

Zlatovic, S., and Ishihara, K. (1995). "On the influence of nonplastic fines on residul strength." Proceedings of IS-TOKY0'95/ The First International Conference on Earthquake Geotechnical Engineering/Tokyo/ 14-16 November 1995, Tokyo, Japan, 239-244. 


\section{Notations:}

$\begin{aligned} e & \text { void ratio } \\ e_{s k e l e t o n}, & \text { Sand skeleton void ratio } \\ e_{g}, & \text { intergranular void ratio } \\ e_{c} & \text { Equivalent granular void ratio } \\ V_{T} & \text { total volume of the specimen } \\ G_{S} & \text { specific gravity of sand } \\ \rho_{w} & \text { density of water } \\ M & \text { total mass of specimen } \\ M_{f} & \text { mass of silt in the specimen } \\ b & \text { active fraction of fines in force structure } \\ f_{c} & \text { fines content in decimal } \\ T F C & \text { threshold fines content in decimal } \\ D & \text { large particle diameter } \\ d & \text { small particle diameter } \\ D_{10} & \text { sand particle diameter at } 10 \% \text { finer } \\ D_{50} & \text { sand particle diameter at } 50 \% \text { finer } \\ d_{50} & \text { fines particle diameter at } 50 \% \text { finer } \\ \chi & \text { particle size ratio, } \chi=D_{10} / d_{50} \\ r & \text { particle size ratio, } r=(1 / \chi)=d_{50} / D_{10} \\ p^{\prime} & \text { mean effective stress, } p^{\prime}=\left(\sigma_{1}{ }^{\prime}+2 \sigma_{3}{ }^{\prime}\right) / 3 \\ q & \text { deviatoric stress, } q=\left(\sigma_{1}{ }^{\prime}-\sigma_{3}{ }^{\prime}\right) \\ & \end{aligned}$


Table 1. Summary of previous research study on sand with fines:

\begin{tabular}{|l|c|c|c|c|c|c|c|}
\hline \multicolumn{1}{|c|}{ Source } & $\begin{array}{c}\text { Sand } \\
\text { particle size }\end{array}$ & $\begin{array}{c}\text { Fines } \\
\text { particle size }\end{array}$ & $\begin{array}{c}\text { Specimen } \\
\text { preparation } \\
\text { method }\end{array}$ & $\begin{array}{c}\text { Fines } \\
\text { Content } \\
(\%)\end{array}$ & $\chi$ & $\begin{array}{c}\text { TFC } \\
(\%)\end{array}$ & $b$-value \\
\hline Yang et al. 2006a & 0.225 & 0.032 & $\mathrm{M}$ & $0-30$ & 7.03 & $30^{*}$ & $0-0.410$ \\
\hline $\begin{array}{l}\text { Huang et al. } \\
\text { 2004 }\end{array}$ & 0.080 & 0.044 & $\mathrm{M}$ & $0-30$ & 1.82 & $41^{*}$ & $0-0.481$ \\
\hline Ni at al. 2004 & 0.209 & 0.038 & $\mathrm{M}$ & $0-09$ & 5.50 & $30^{\dagger}$ & $0-0.021$ \\
\hline $\begin{array}{l}\text { Zlatovic and } \\
\text { Ishihara 1995 }\end{array}$ & 0.116 & 0.01 & $\mathrm{M} / \mathrm{DD} / \mathrm{WS}$ & $0-30$ & 11.60 & $33^{\dagger}$ & $0-0.360$ \\
\hline $\begin{array}{l}\text { Thevanayagam } \\
\text { et a.1 2002 }\end{array}$ & 0.160 & 0.010 & $\mathrm{~A} / \mathrm{M}$ & $0-25$ & 16.00 & $36^{*}$ & $0-0.280$ \\
\hline Vaid 1994 & 0.070 & 0.007 & $\mathrm{SD}$ & $0-21$ & 10.00 & $32^{\dagger}$ & $0-0.276$ \\
\hline Polito, P.C. 1999 & 0.089 & 0.031 & $\mathrm{M}$ & $0-37$ & 2.87 & $30^{*}$ & $0-0.389$ \\
\hline $\begin{array}{l}\text { Polito and Martin } \\
\text { 2001 }\end{array}$ & 0.311 & 0.031 & $\mathrm{M}$ & $0-25$ & 10.03 & $32^{*}$ & $0-0.321$ \\
\hline $\begin{array}{l}\text { Thevanayagam } \\
\text { and Martin 2002 }\end{array}$ & 0.160 & 0.010 & $\mathrm{~A} / \mathrm{M}$ & $0-25$ & 16.00 & $36^{*}$ & $0-0.280$ \\
\hline $\begin{array}{l}\text { Authors, } \\
\text { Bobei and Lo } \\
\text { (2005 }\end{array}$ & 0.225 & 0.006 & $\mathrm{M}$ & $0-20$ & 40.00 & $40^{\dagger}$ & $0-0.195$ \\
\hline
\end{tabular}

$\mathrm{M}=$ Moist tamping method, $\mathrm{A}=$ Air pluviation method, $\mathrm{DD}=$ Dry deposition, $\mathrm{WS}=$ Water sedimentation, $\mathrm{SD}=\mathrm{Slurry}$ deposition

* Obtained from source data following the procedure described in section 3.3

$\dagger \quad$ Calculated value from Eqn. (6)

$\otimes \quad b$-value depends on fines content 


\section{LIST OF FIGURES}

Figure 1. Effect of fines content on minimum void ratio of binary mix (After Lade et al. 1998)

Figure 2. Effect of diameter ratio on minimum void ratio of binary mix (After Lade et al. 1998)

Figure 3. Effect of fines on the location of SSL (Thevanayagam et al. 2002)

Figure 4. Change in critical state void ratio, $e_{100}$ with increasing fines content.

Figure 5. Factors affecting $b$; (a) Influence of $\chi$ on $b$, (b) Influence of fines content on $b$ for TFC=0.35

Figure 6. Relation between TFC and particle diameter ratio, $\chi$

Figure 7. Steady state lines for Hokksund sand with Chengbei non-plastic fines in terms of equivalent granular void ratio and void ratio (after Yang et al. 2006a)

Figure 8. Steady state lines for Mai Liao sand with fines in terms of equivalent granular void ratio and void ratio (after Huang et al. 2004)

Figure 9. Steady state lines for Old Alluvium sand with fines in terms of equivalent granular void ratio and void ratio (after $\mathrm{Ni}$ et al. 2004)

Figure 10. Steady state lines for Toyoura sand with fines in terms of equivalent granular void ratio and void ratio (after Zlatovic and Ishihara 1995)

Figure 11. Steady state lines for Foundry sand with non-plastic fines in terms of equivalent granular void ratio and void ratio (after Thevanayagam et al. 2002)

Figure 12. Cyclic Resistance for 20/200 Brenda sand with silty fines in terms of equivalent granular void ratio and void ratio (after Vaid 1994)

Figure 13. Cyclic resistance for Yatesville sand with fines in terms of equivalent granular void ratio and void ratio (after Polito 1999)

Figure 14. Cyclic resistance for Montereysand and Yatesville fines in terms of equivalent granular void ratio and void ratio (after Polito and Martin 2001)

Figure 15. No. of cycles $\left(\mathrm{N}_{\mathrm{L}}\right)$ required to trigger cyclic liquefaction for Ottawa sand with non-plstic fines at cyclic stress ratio of 0.20 in terms of equivalent granular void ratio and void ratio (after Thevanayagam and Martin 2002)

Figure 16. Comparison between SSL form triaxial test and prediction formula for Foundry sand with $25 \%$ crushed silica (after Thevanayagam et al. 2002)

Figure 17. Comparison between SSL form triaxial test and prediction formula for Sydney sand with $10 \%$ and $20 \%$ Majura fines 


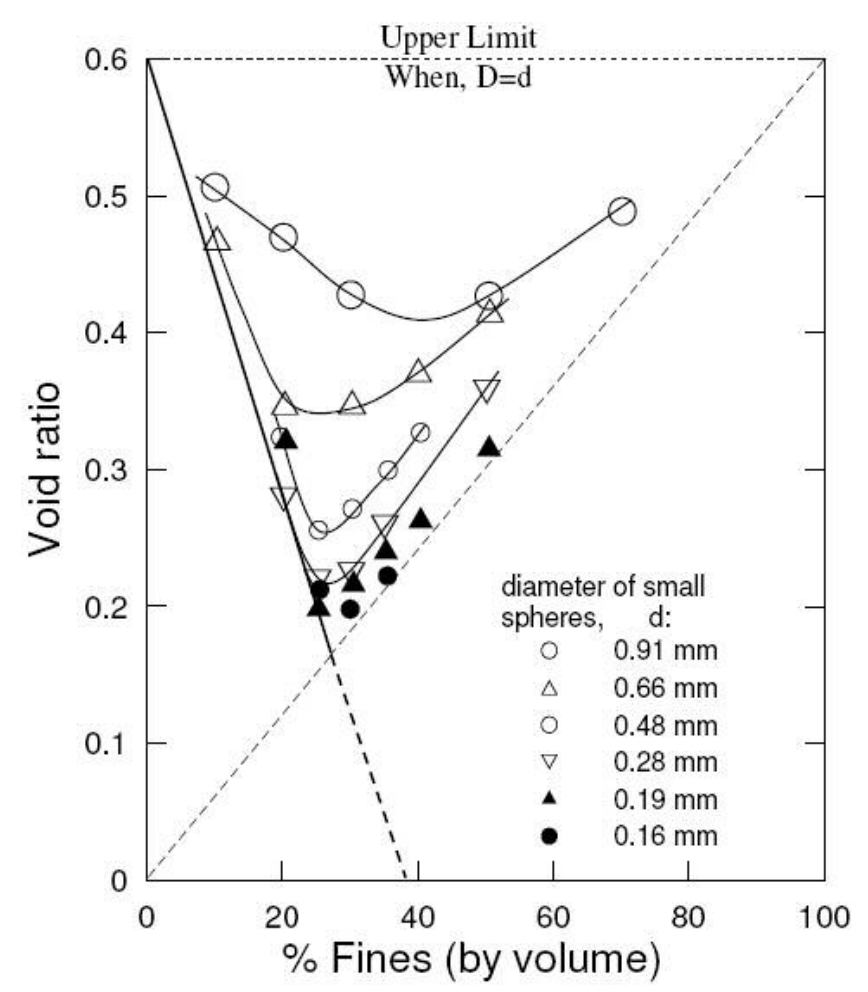

Diameter of large sphere, $\mathrm{D}=3.15 \mathrm{~mm}$

Most densely packed relationship for small spheres in a matrix of large spheres Most densely packed relationship for large spheres in a matrix of small spheres

Figure 1. Effect of fines content on minimum void ratio of binary mix (After Lade et al. 1998).

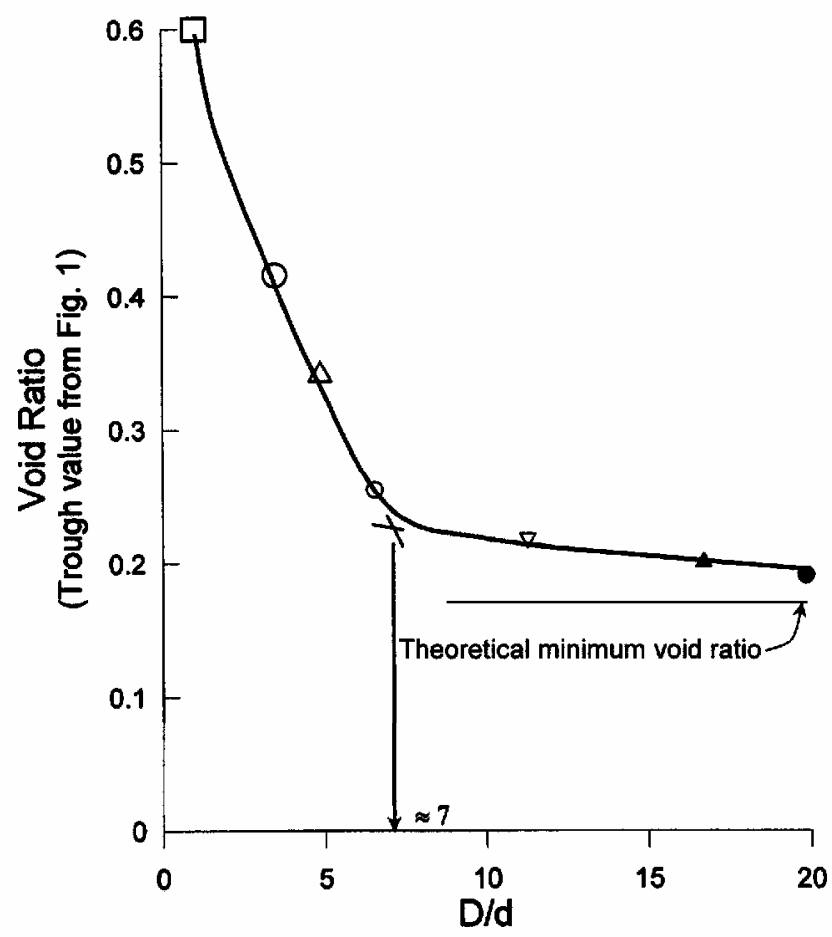

Figure 2. Effect of diameter ratio on minimum void ratio of binary mix (After Lade et al. 1998) 


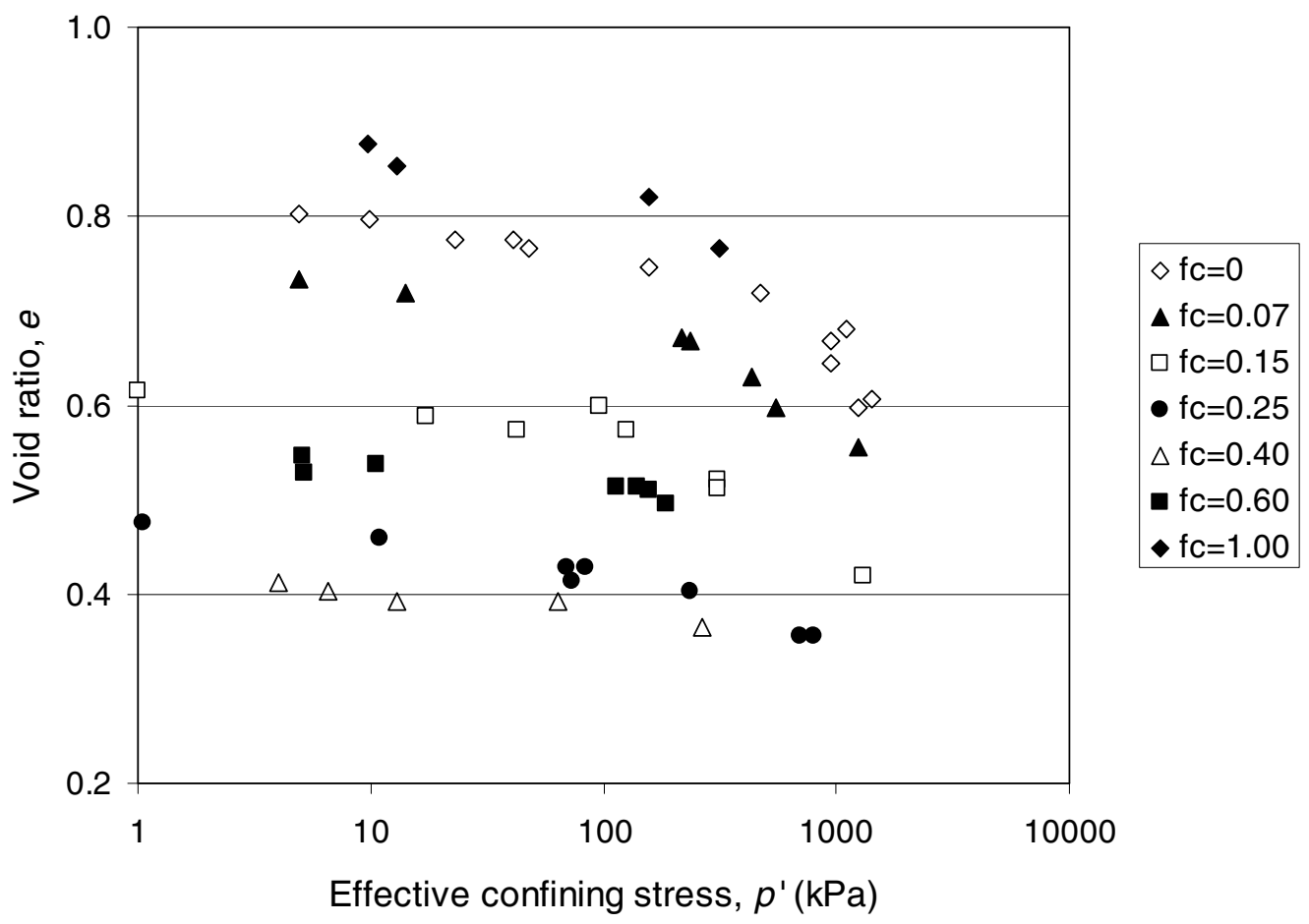

Figure 3. Effect of fines on the location of SSL (Thevanayagam et al. 2002)

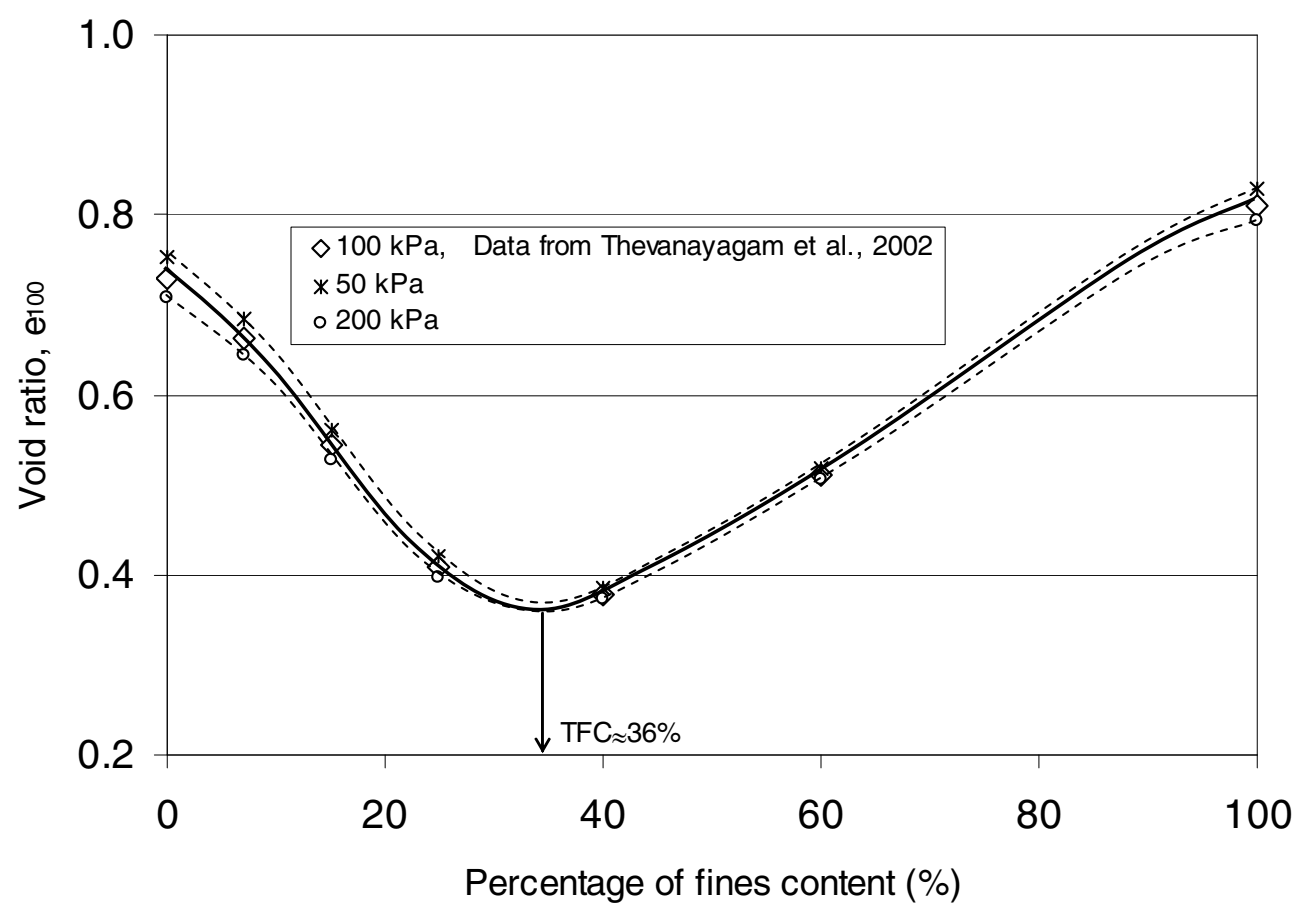

Figure 4. Change in critical state void ratio, $e_{100}$ with increasing fines content. 


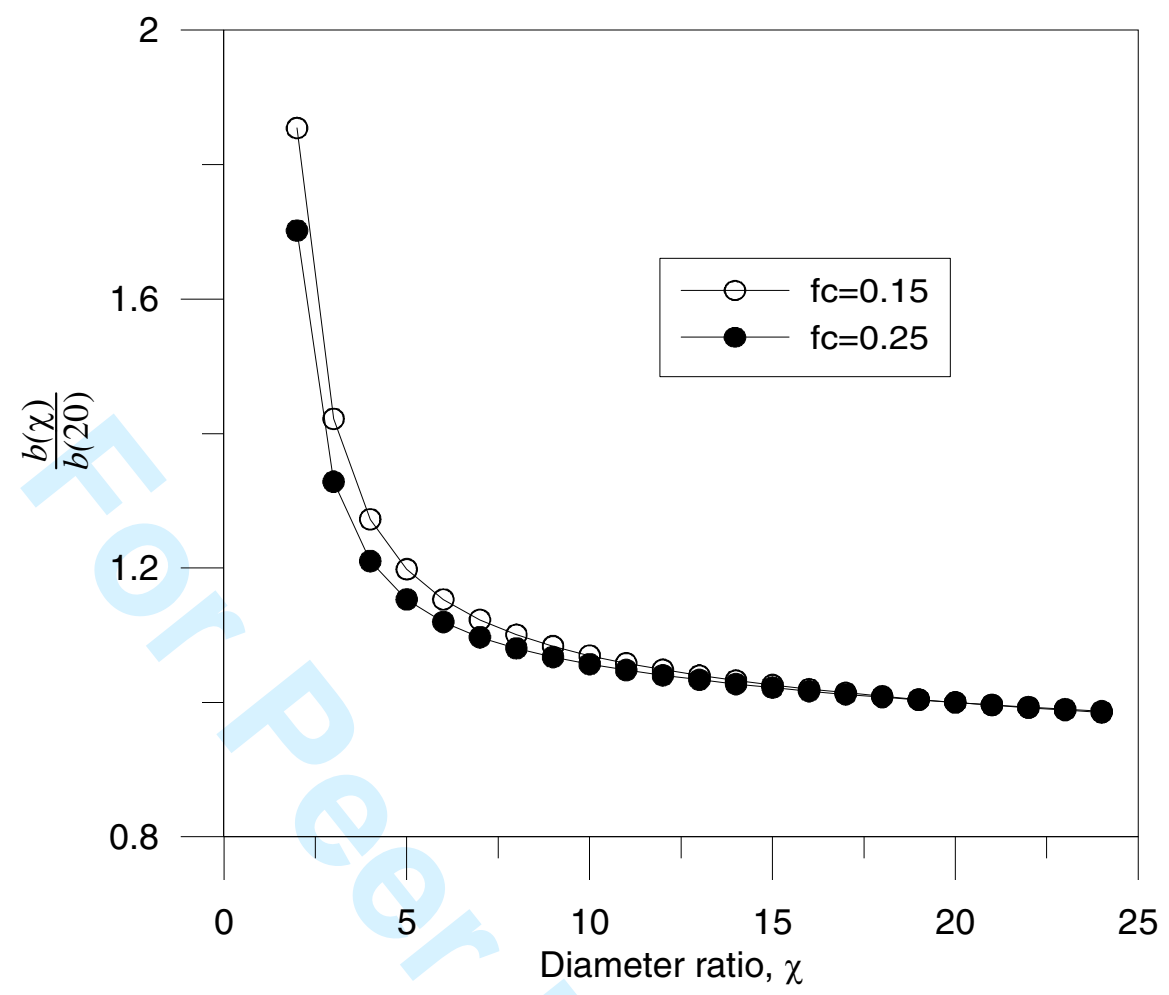

(a) Influence of $\chi$ on $b$

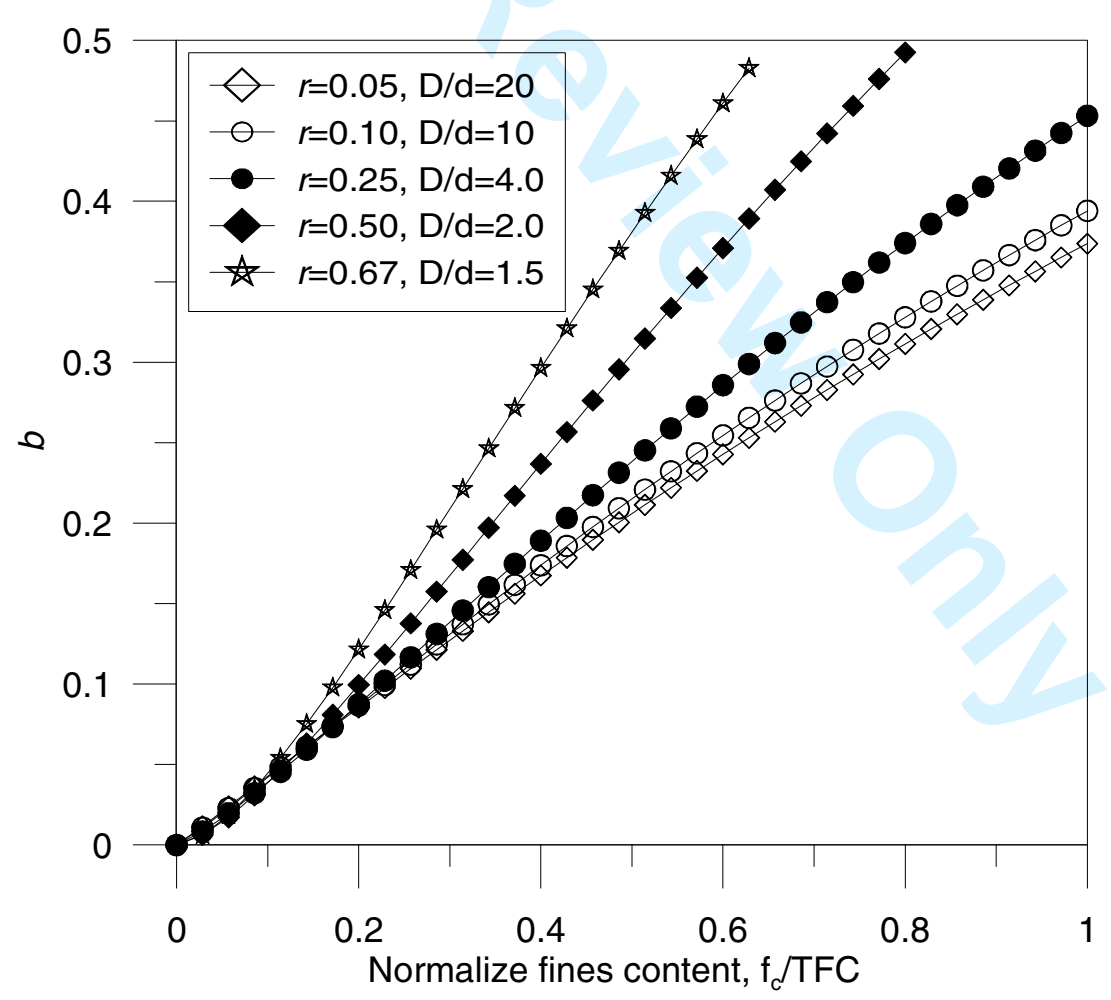

(b) Influence of fines content on $b$

Figure 5. Factors affecting $b$; (a) Influence of $\chi$ on $b$, (b) Influence of fines content on $b$ for TFC $=0.35$ 


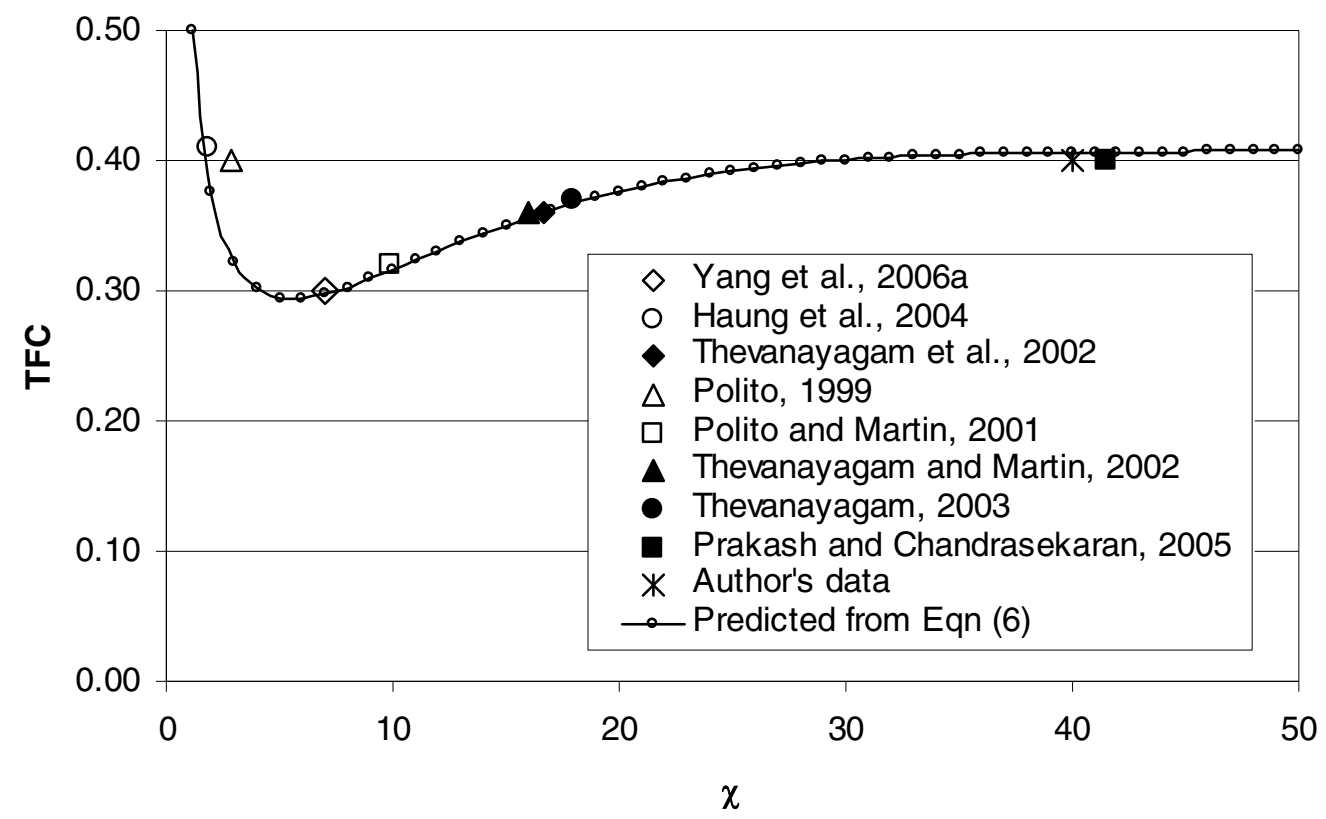

Figure 6. Relation between TFC and particle diameter ratio, $\chi$.

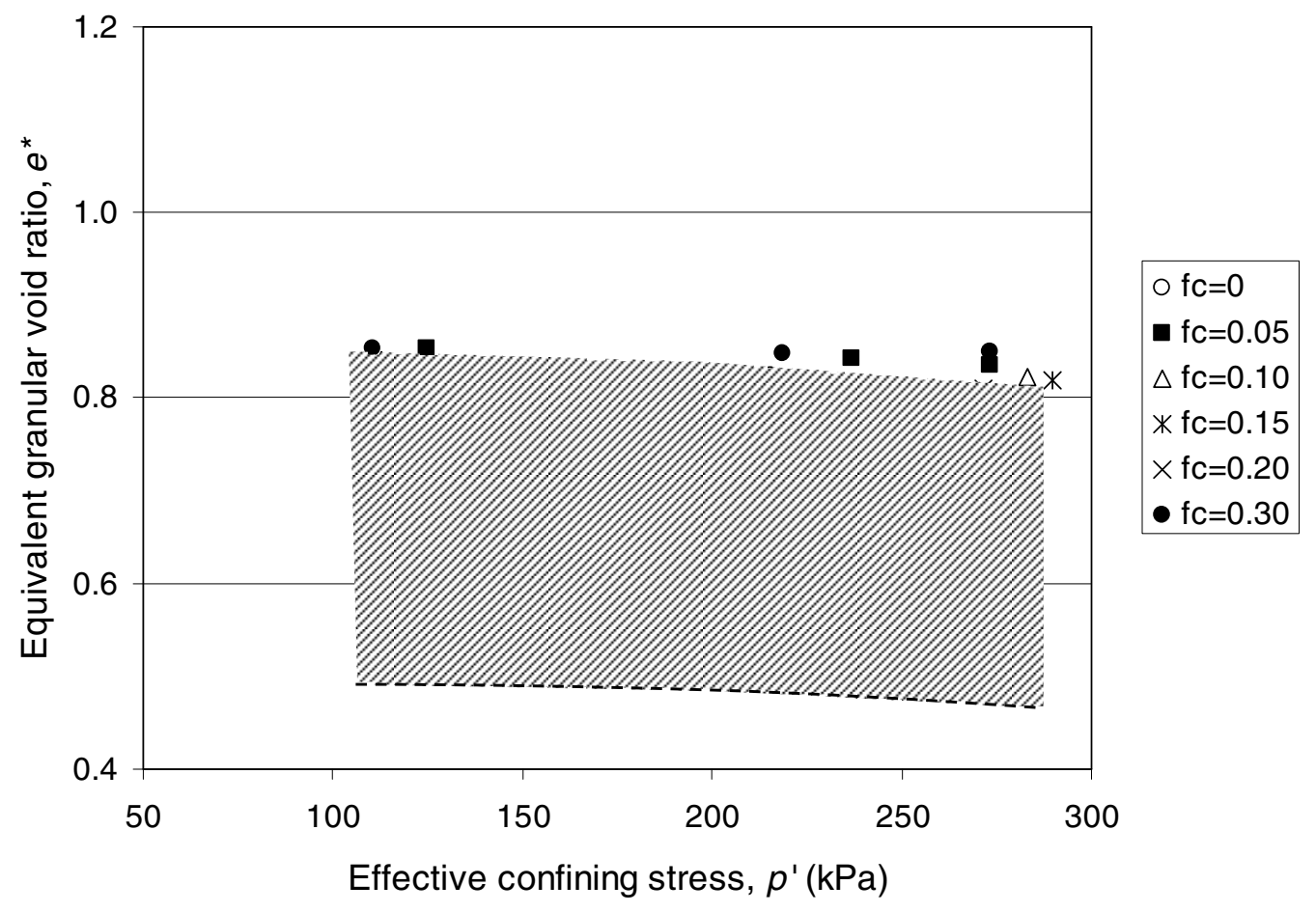

Figure 7. Steady state lines for Hokksund sand with Chengbei non-plastic fines in terms equivalent granular void ratio and void ratio (after Yang et al. 2006a) 


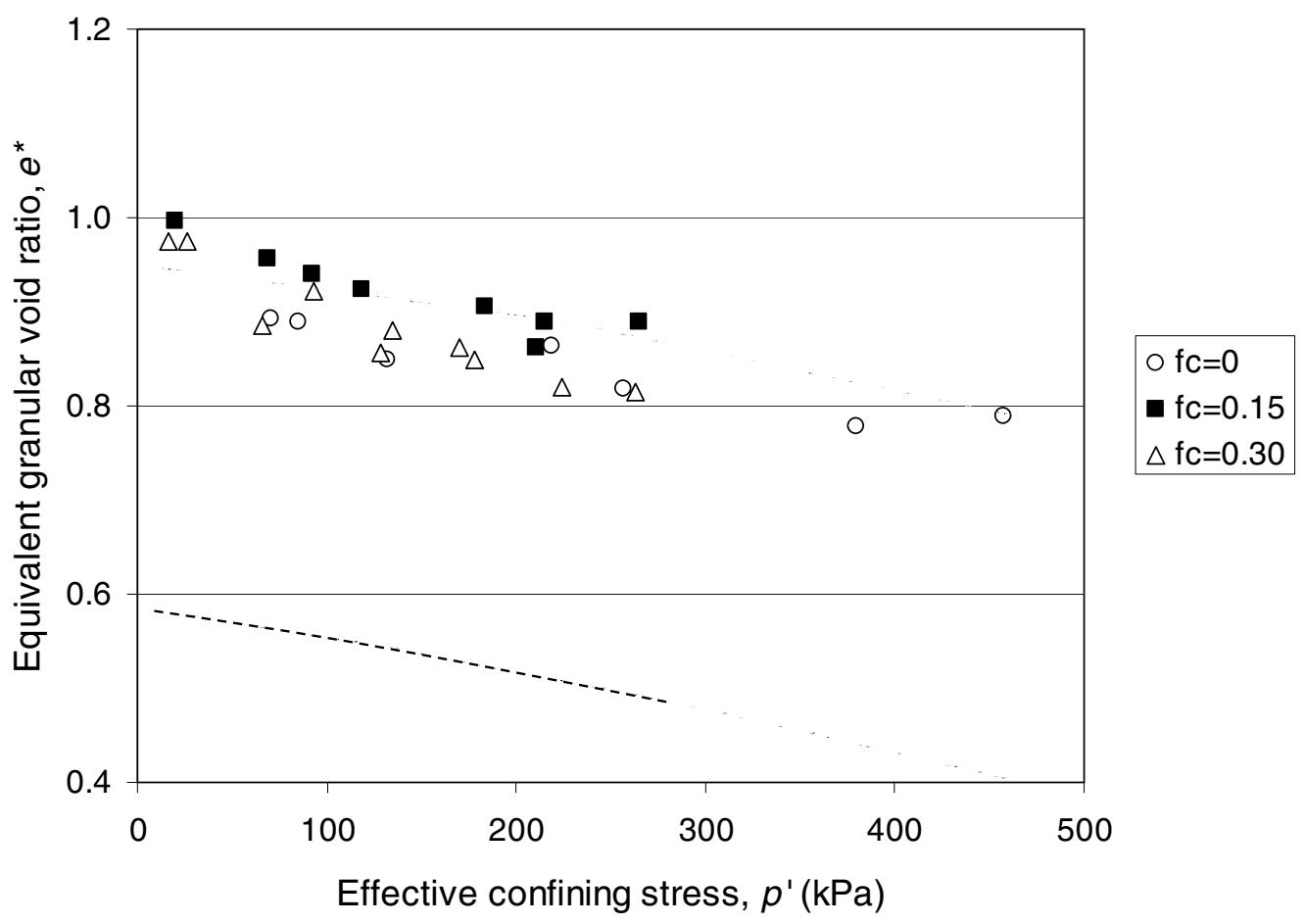

Figure 8. Steady state lines for Mai Liao sand with fines in terms of equivalent granular void ratio and void ratio (after Huang et al. 2004)

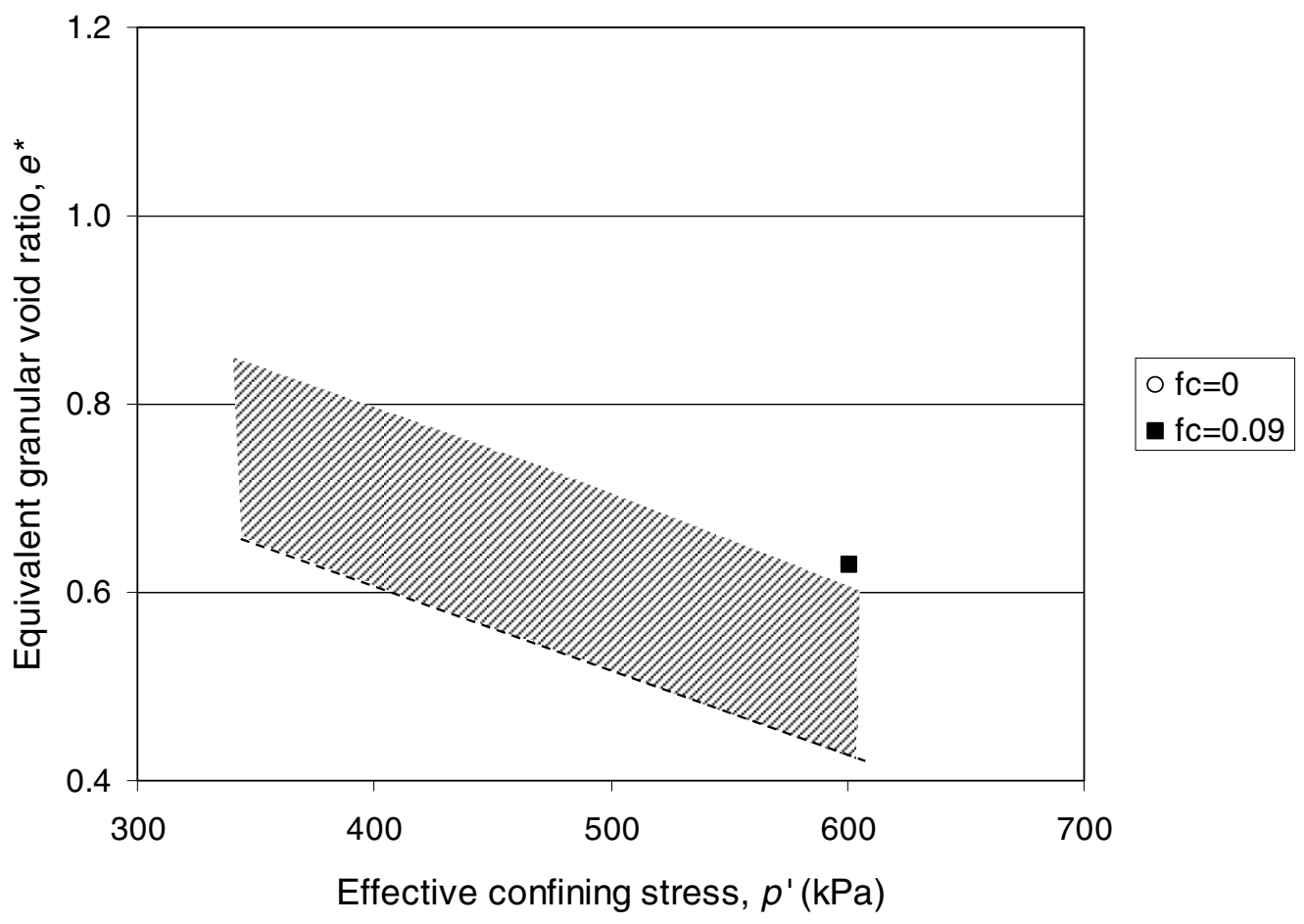

Figure 9. Steady state lines for Old Alluvium sand with fines in terms of equivalent granular void ratio and void ratio (after Ni et al. 2004) 


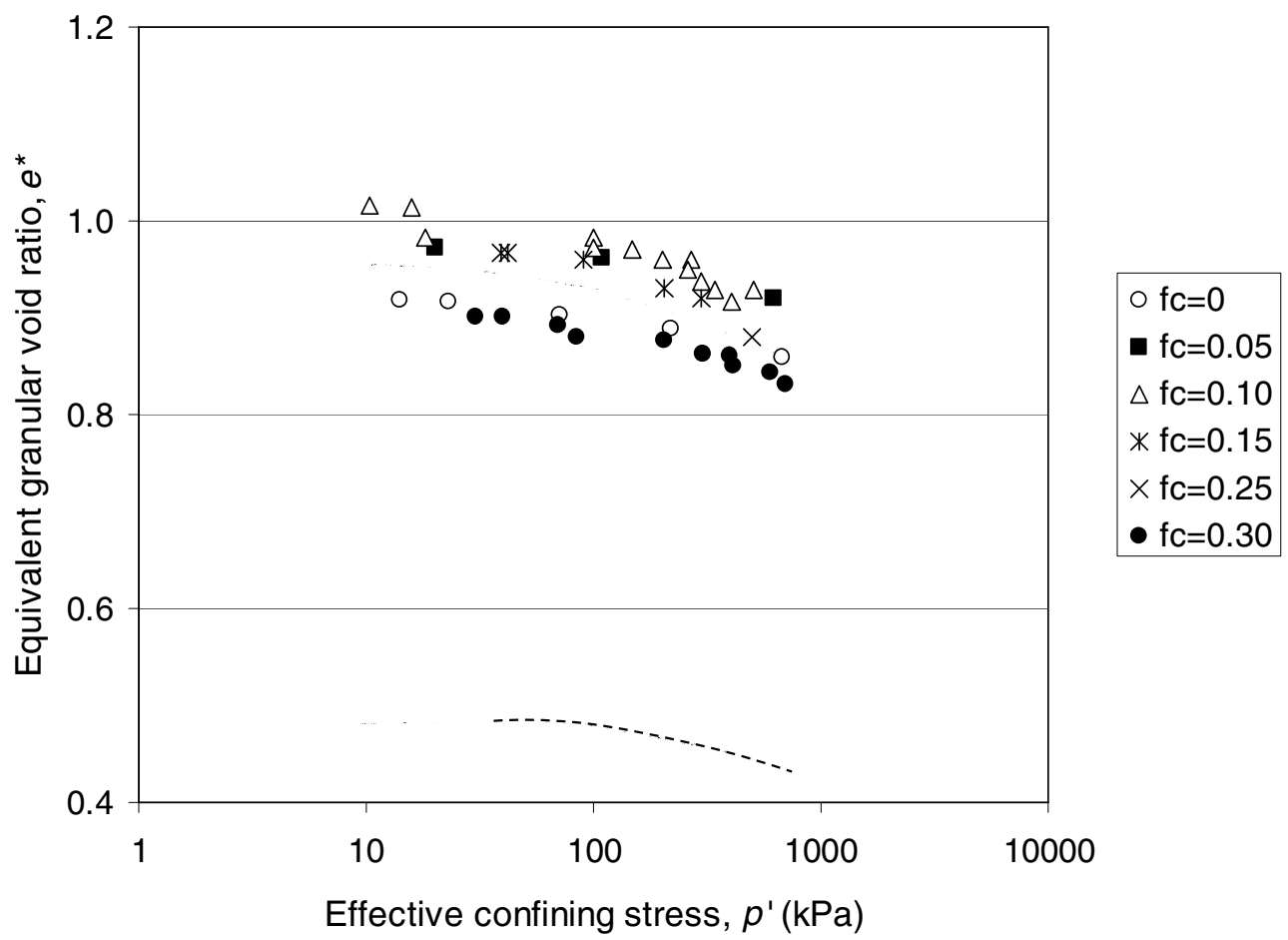

Figure 10. Steady state lines for Toyoura sand with fines in terms of equivalent granular void ratio and void ratio (after Zlatovic and Ishihara 1995)

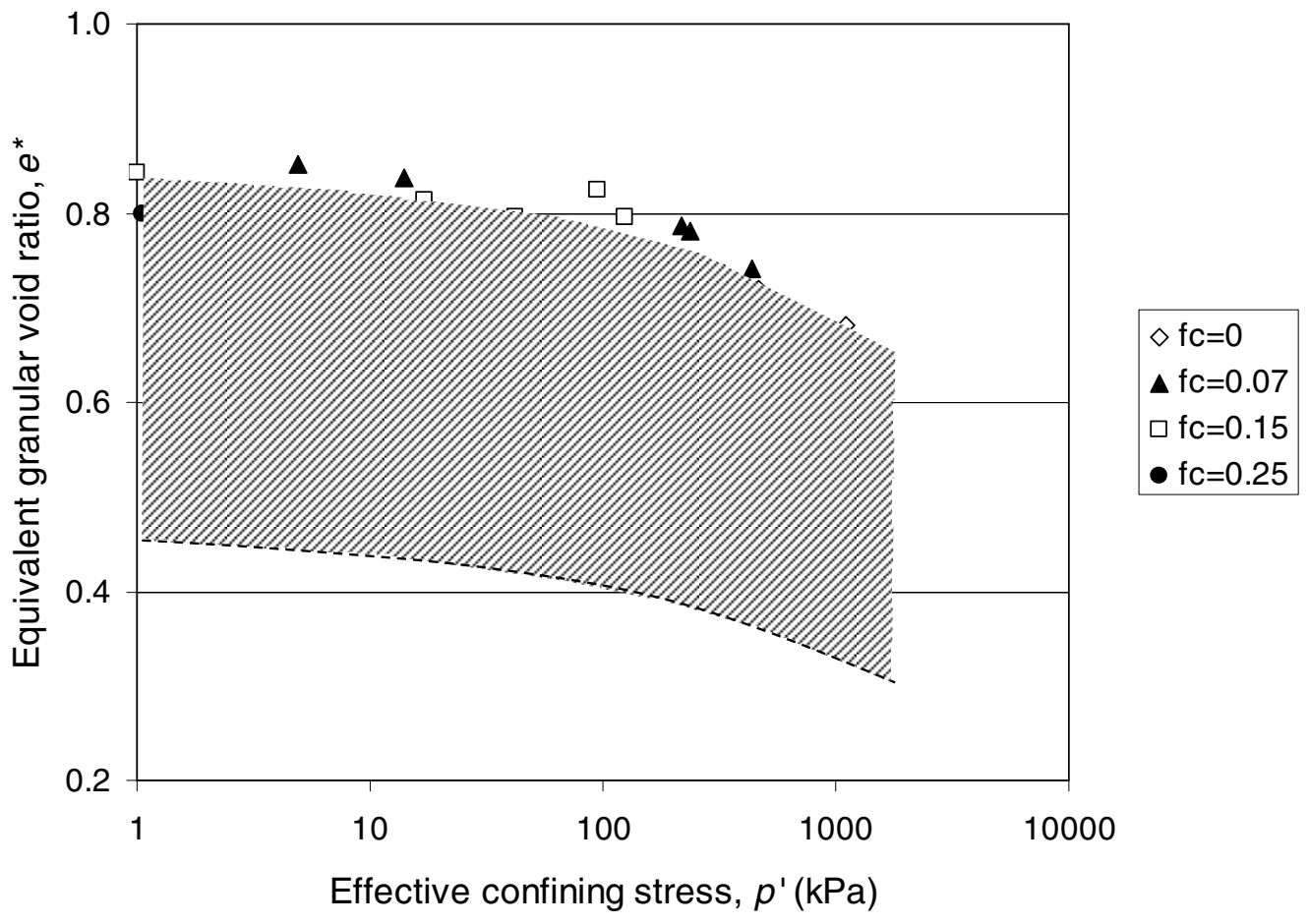

Figure 11. Steady state lines for Foundry sand with non-plastic fines in terms of equivalent granular void ratio and void ratio (after Thevanayagam et al. 2002) 


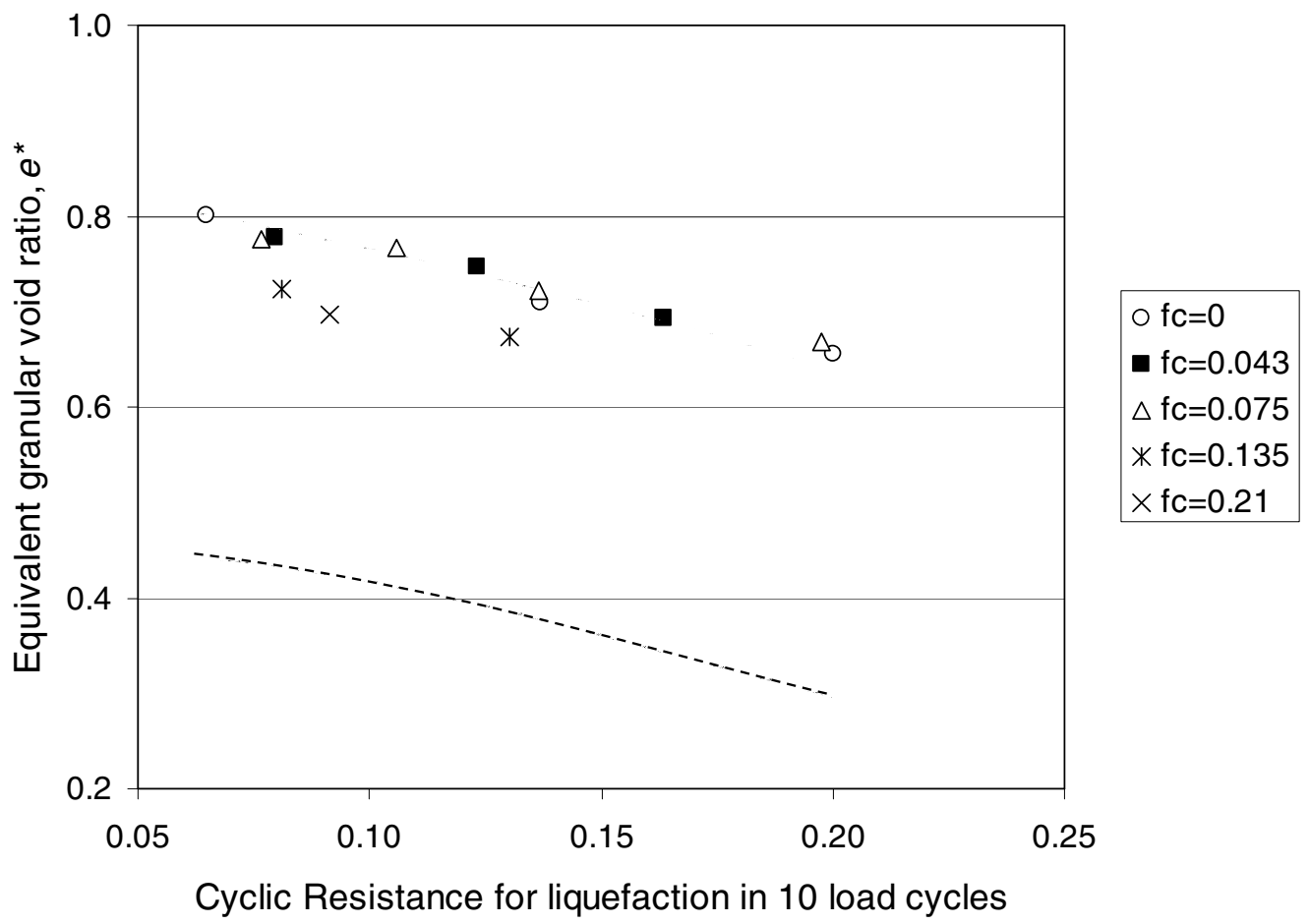

Figure 12. Cyclic Resistance for 20/200 Brenda sand with silty fines in terms of equivalent granular void ratio and void ratio (after Vaid 1994)

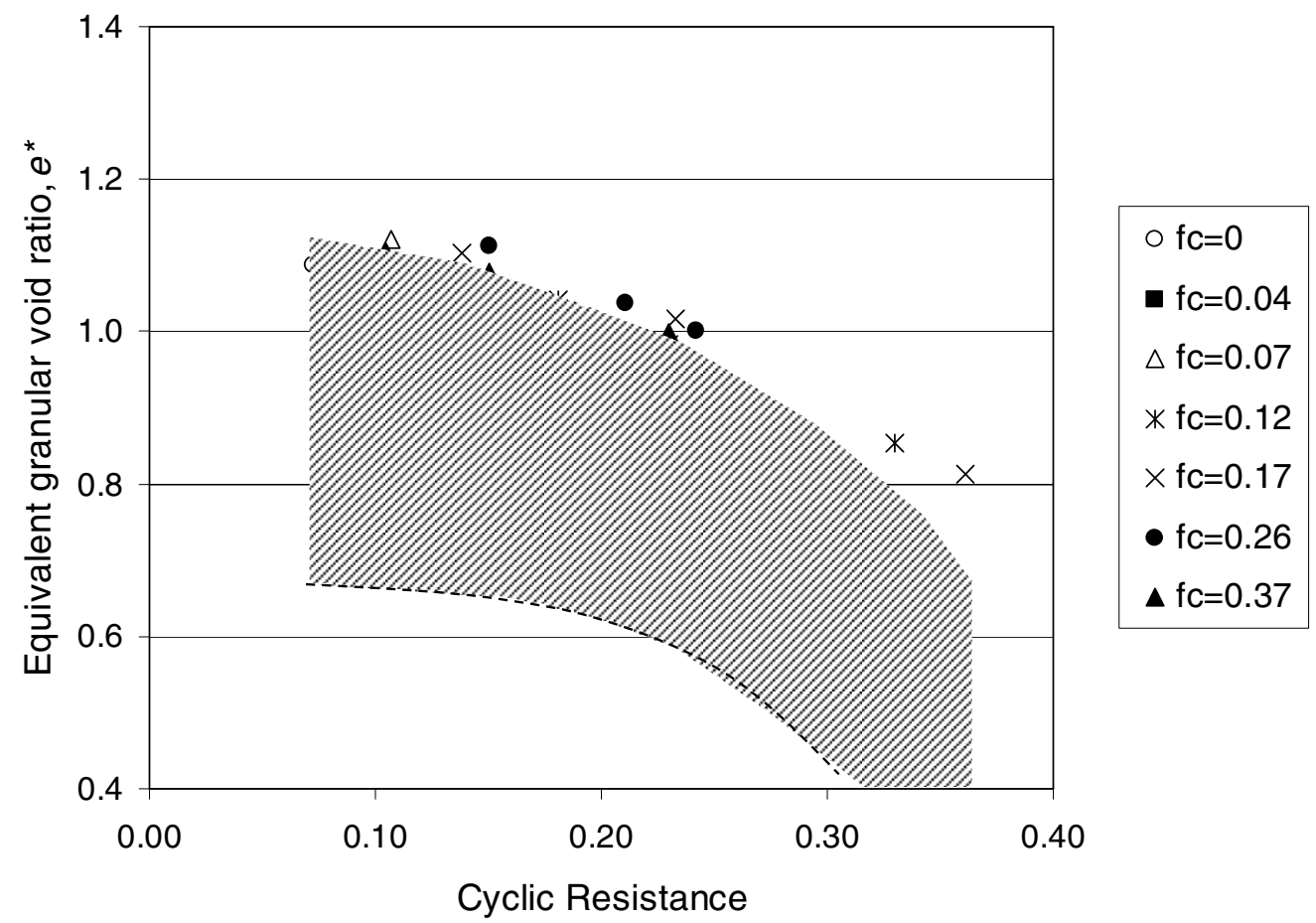

Figure 13. Cyclic resistance for Yatesville sand with fines in terms of equivalent granular void ratio and void ratio (after Polito 1999) 


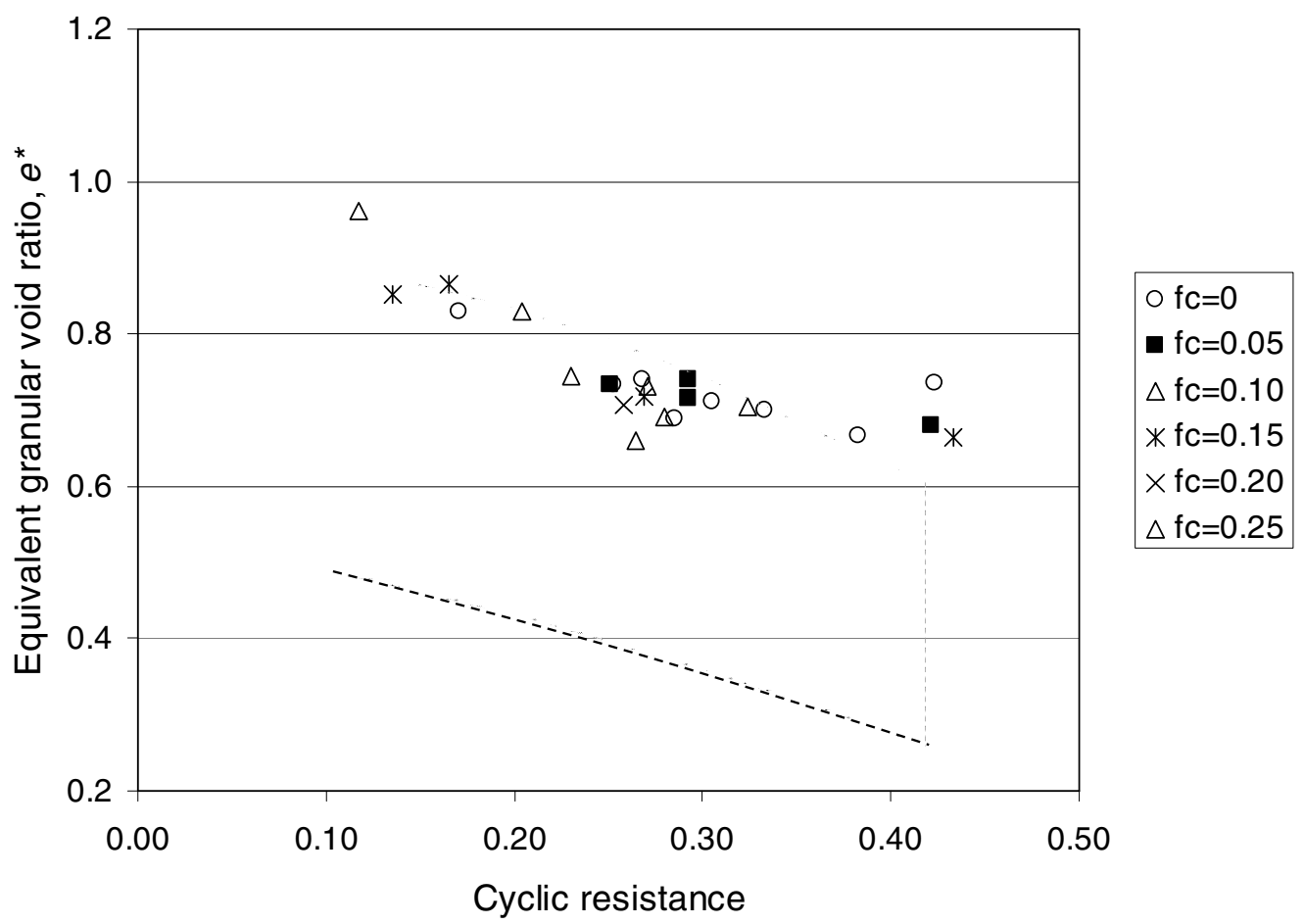

Figure 14. Cyclic resistance for Montereysand and Yatesville fines in terms of equivalent granular void ratio and void ratio (after Polito and Martin 2001)

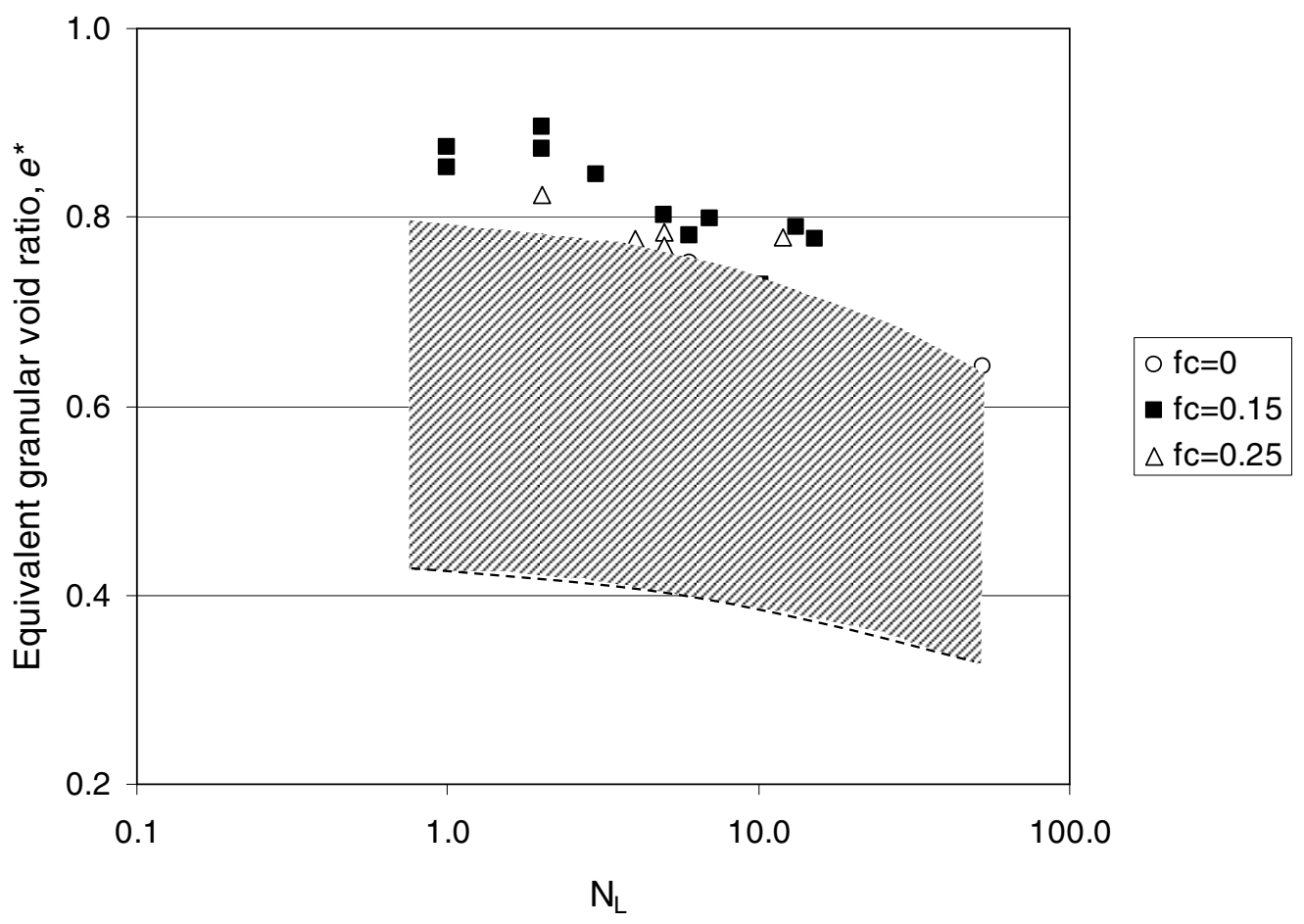

Figure 15. No. of cycles (NL) required to trigger cyclic liquefaction for Ottawa sand with non-plastic fines at cyclic stress ratio of 0.20 in terms of equivalent granular void ratio and void ratio (after Thevanayagam and Martin 2002) 


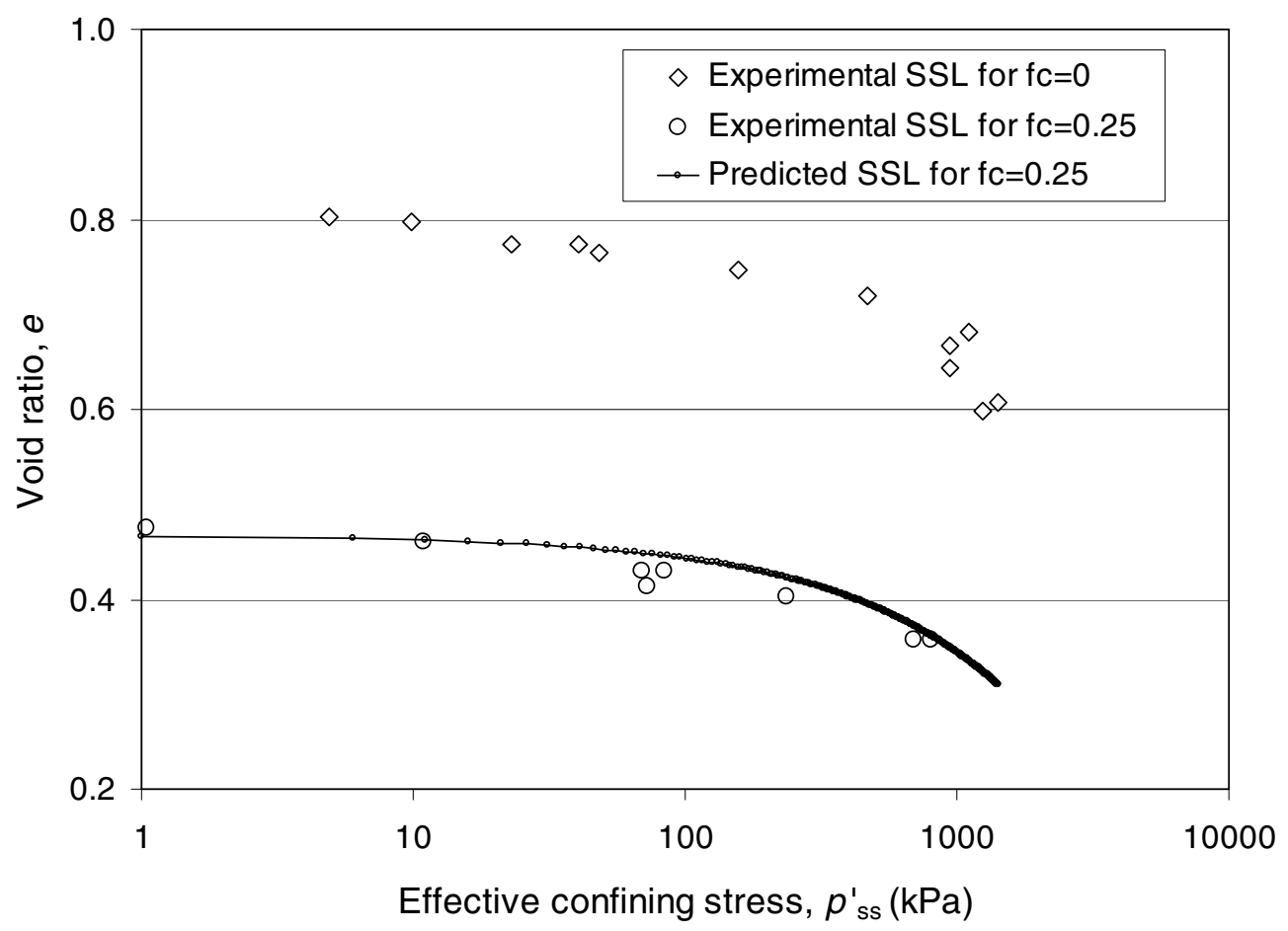

Figure 16. Comparison between SSL form triaxial test and prediction formula for Foundry sand with 25\% crushed silica (after Thevanayagam et al. 2002). 


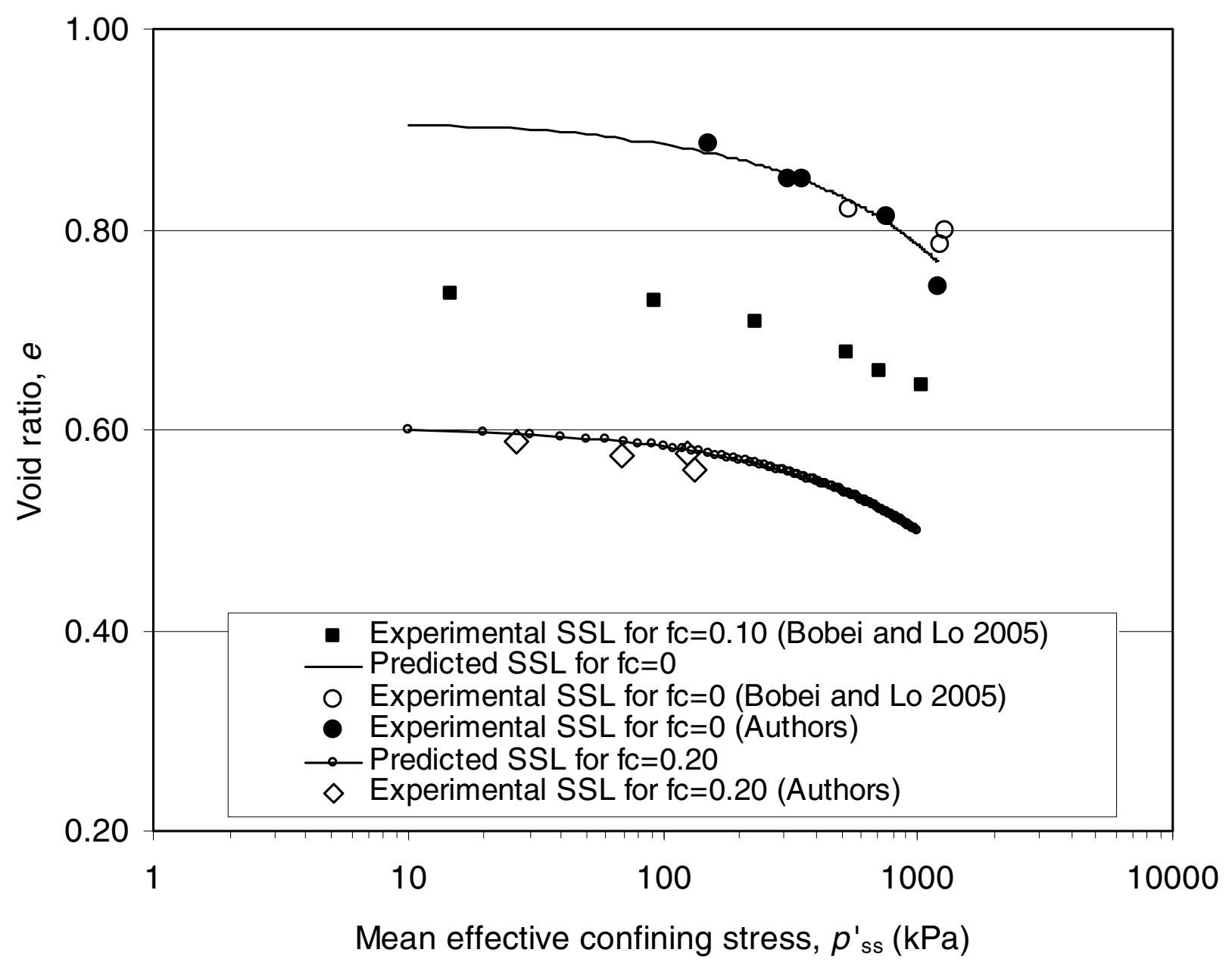

Figure 17. Comparison between SSL form triaxial test and prediction formula for Sydney sand with $10 \%$ and $20 \%$ Majura fines. 


\section{REVIEWER- 1}

\section{General Comments}

No action needed

\section{Specific Comments}

1. The revised manuscript was thoroughly edited.

2. Extra citations were included.

3. The inferring of the mathematical attributes of function $b=F\left(\chi, f_{\mathrm{c}}\right)$ was added to Sect-3.1.

4. Eqn (5) is a semi-empirical relationship that was established based on the 4 mathematical attributes. The rationale is clarified in the revised manuscript.

5. It will be acknowledged in the revised manuscript that TFC was derived based on the reversal point at $p^{\prime}$ ss of $100 \mathrm{kPa}$. We also showed, in the revised manuscript that this reversal point (hence the deduced TFC) is not sensitive to $p_{\text {SS }}^{\prime}$.

6. $\quad b$-values will be included in Table .

7. These TFC values were deduced from the source data following the procedure of Sect-3.3 (not using the eqn developed in Sect-3.5). This will be clarified in the revised manuscript.

8. It will be explicitly stated in the revised manuscript that a unique $e^{*}-\log \left(p^{\prime}\right)$ relationship is the assumed conceptual framework.

The process of deducing $m=0.3$ from the source data of Thevanayagam et al. (2002) is detailed in the revised thesis. Please note that statistical principle was adopted.

9. The limitations of the findings are now clearly stated in the revised manuscript.

10. Agree with the comment that a single equivalent granular SSL is used as an assumption for establishing the b-values.

Philosophically, a single equivalent SSL is a requirement set in this research. If this requirement cannot be satisfied, than $\mathrm{e}^{*}$ and $\mathrm{b}$ have little significance. This bullet point will be re-stated as: "The requirement of a single steady state line irrespective of fines content in the equivalent granular void ratio versus effective mean stress space can be achieved by Eqns (4) and (5a)".

11. The definition of $\mathrm{N}_{\mathrm{L}}$ was recalled in the conclusion section of the revised manuscript. 


\section{REVIEWER- 1}

\section{General Comments}

No action needed

\section{Specific Comments}

Comments $1-7$ :

suggested editorial corrections made.

Comment 8:

a short paragraph added to conclusion section to re-iterate that the influence of actual deposition environment may affects the findings.

Comments $9-13$ :

suggested editorial corrections made.

Comment 14:

the definition of cyclic stress ratio and cyclic resistance added to the revised manuscript as suggested. As their definitions are quite elaborate, its added to Appendix-A.

Comments 15-16:

suggested editorial corrections made.

Comment 17:

The calculation procedure for example 2, including the sentence highlighted by the reviewer, was re-written for better clarity.

Comment 18:

A short "summary statement" was added at the beginning of the Conclusion section as suggested.

Comment 19-20:

suggested editorial corrections made.

Comment 21:

The two lines in Fig. 1were made more distinguishable by re-plotting them as a solid line and a dash line. 